\title{
Neutron Irradiation Effects on Carbon and Graphite Cloths and Fibers
}

by

w. J. Gray

August 1977

Prepared for the Energy Research and Development Administration under Contract EY-76-C-06-1830 
NOTICE

This report was prepared as an account of work sponsored by the United States Government. Neither the United States nor the Energy Research and Development Administration, nor any of their employees, nor any of their contractors, subccntractors, or their employees, makes any warranty, express or implied, or assumes any legal liability or responsibility for the accuracy, completeness or usefulness of any information, apparatus, product or process disclosed, or reprisents that its use would not iniringe privately owned rights.

The views, opinions and conclusions contained in this report are those of the contractor and do not necessarily represint those of the United States Covernment or the Unired States Energy Research and Development Administration.

PACIFIC NORTHWEST LABORATORY

operated by

BATTELLE

for the

ENERGY RESEARCH AND DEVELOPMENT ADMINISTRATION

Under Contract EY-76-C-06-1830

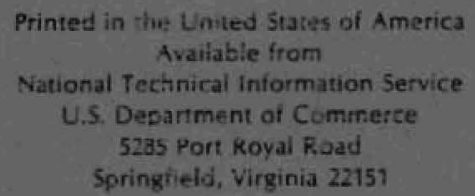

Price: Printed Copy 5

$\because$ Microfiche $\$ 3.00$

$\begin{array}{cc}\text {-Pages } & \text { NTIS } \\ \text { Selling Price } \\ 001-025 & \$ 4.50 \\ 026.059 & \$ 5.00 \\ 051-075 & \$ 5.50 \\ 076-100 & \$ 6.00 \\ 101-125 & \$ 6.50 \\ 125-150 & \$ 7.00 \\ 151-175 & \$ 7.75 \\ 176-200 & \$ 8.50 \\ 201-225 & \$ 8.75 \\ 226-250 & \$ 9.00 \\ 151-275 & \$ 10.00 \\ 276-100 & \$ 10.25\end{array}$


NEUTRON IRRADIATION EFFECTS ON CARBON AND GRAPHITE CLOTHS AND FIBERS

by

W. J. Gray

Ceramics and Graphite Section Materials Department

August 1977

Battelle

Pacific Northwest Laboratories

Richland, Washington 99352 


\section{TABLE OF CONTENTS}

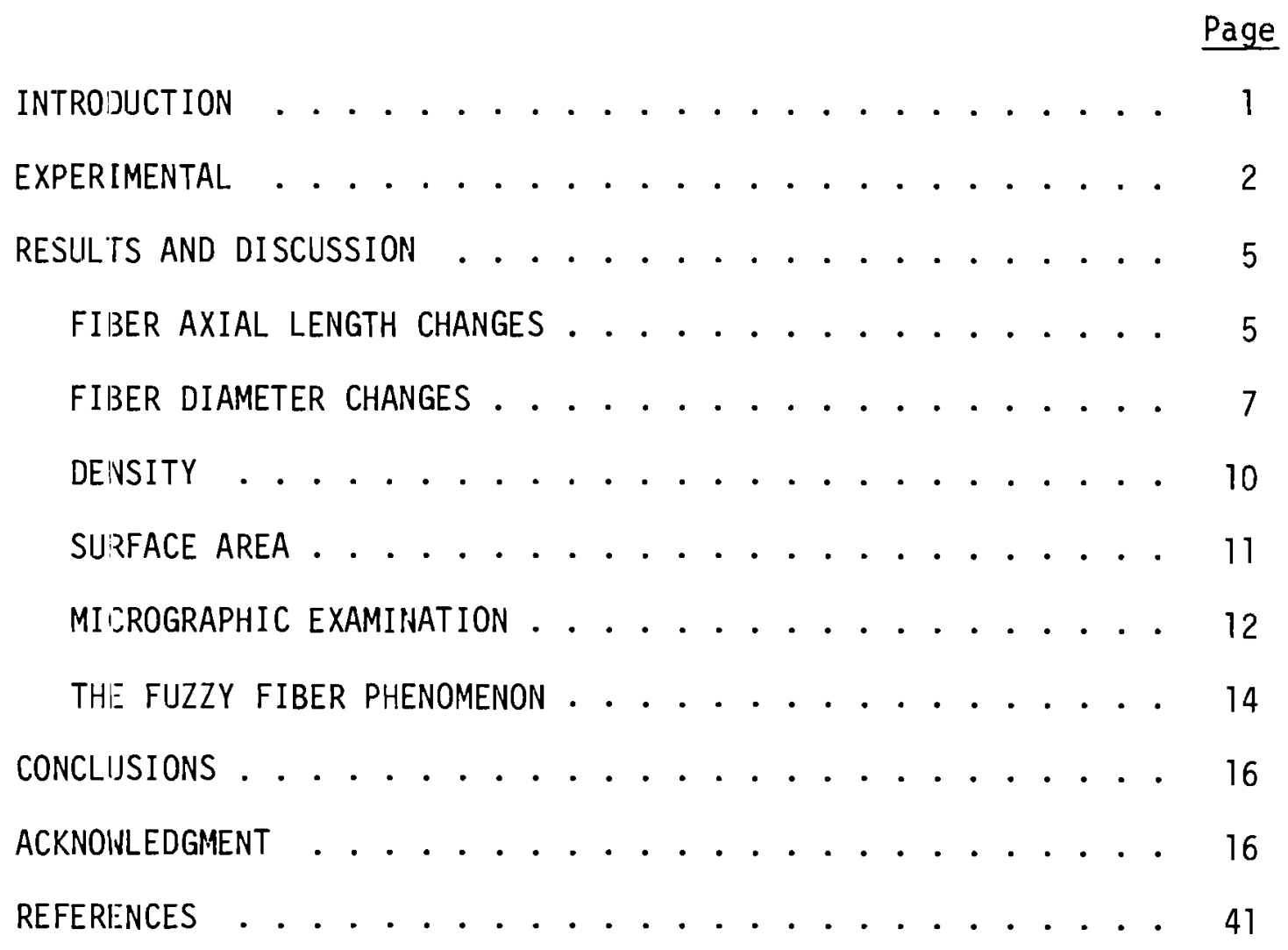




\title{
NEUTRON IRRADIATION EFFECTS ON \\ CARBON AND GRAPHITE CLOTHS AND FIBERS
}

\author{
W. J. Gray
}

A series of cloth and fiber samples were irradiated to fluences of 3.5 , 7.3, and $10 \times 10^{21} \mathrm{~cm}^{-2}$ at $470^{\circ} \mathrm{C}$. Dimensional changes of the fibers in the radiai airection ranged from $-19 \%$ to $+33 \%$ and in the axiai airection from $-18 \%$ to $-27 \%$, roughly ten times greater than dimensional changes found for typical nuclear graphites. Despite these large dimensional changes, all but one of the 2-dimensional cloths remained essentially unchanged in overall physical appearance. The 3-dimensional cloths, on the other hand, deteriorated apparently because these types of weaves were less able to accommodate the large axial fiber shrinkages.

\section{INTRODUCTION}

Carbon or graphite cloth has been suggested for use in fusion reactors between the plasma and the first structural wal1. (1,2) Thin cloths would minimize high-Z impurities within the plasma by providing a barrier which would prevent ions and neutral atoms from striking the wall, and they would keep neutron-sputtered high-Z atoms from entering the plasma. Thick cloths would serve the additional function of slowing down the high-energy neutrons thereby reducing radiation damage, particularly helium production, in the first structural wal1. The concept of using a low- $Z$ liner to minimize high-Z impurities in the plasma is valid whether one uses cloths or solid slabs of graphite or other low-Z materials.

While the amount of neutron irradiation data on solid graphites is very extensive (e.g., refs. 3-8), it is almost nonexistent on carbon or graphite cloth. A few papers (e.g., refs. 9-13) deal with structural and mechanical property changes of cloths at maximum fluences up to $21 \times 10^{21} \mathrm{~cm}^{-2} \star$.

\footnotetext{
*A11 fluences arequoted in terms of "Equixalent Fission Fluence for Damage in Graphite." (14) A fluence of $1.01 \times 10^{21} \mathrm{~cm}^{-2}$ produces one displacement per atom (dpa) in graphite.(15)
} 
Dimensional clanges will probably be the most important for fusion reactor applications, however, and there is only one paper (16) where dimensional changes of irradiated fibers have been reported. In that work, where three types of fibers were irradiated, the extreme case was for Thorne1-50s whose diameters inc'neased about $50 \%$ after irradiation to $21.5 \times 10^{21} \mathrm{~cm}^{-2}$ at $400-700^{\circ} \mathrm{C}$.

Obviously a great deal of irradiation data measured under fusion reactor conditions (temperatures up to $2000^{\circ} \mathrm{C}$ and fluences at least up to $1 \times 10^{22} \mathrm{~cm}^{-2}$ and perhaps a factor of 5 to 10 higher) will be required to determine whether any of the various fibrous materials will be suitable for such applications. As a start on obtaining these data, three series of cloths and fibers were irradiated in EBR-II in three different capsules to fluences of $3.5,7.3$, and $10 \times 10^{21} \mathrm{~cm}^{-2}$ at $470^{\circ} \mathrm{C}$. Results from the first of these capsules were reported earlier. (17) The present paper constitutes the final report on these irradiations and includes inesults from all three capsules.

\section{EXPERIMENTAL}

The preparation and properties of fibrous carbon and graphite materials have been described by Kulcinski et al. (1) Briefly, the preparation involves the controlled thermal conversion (pyrolysis) of precursor organic fibers to residual carbonaceous material. Organic precursors typically used are either rayon or polyacrylonitrile (PAN). More recently, pitches have been used as precursors. (18) The pyrolysis may be done on a pre-woven cloth or, alternatively, the fibers may be pyrolyzed prior to the weaving of the cloth. Materials referred to as carbons are produced by pyrolysis at relatively low temperatures, $\leq 1000^{\circ} \mathrm{C}$. Graphite products result from an additional step in which the temperature is raised to $2000^{\circ} \mathrm{C}$ or more. Cloth may be either 2- or 3-dimensional. The former is a relatively thin single layer of fabric prepared by some type of simple under and over weave. The much thicker 3-D materials, schematic diagrams of which are shown in Figure 1, are prepared by means of specialized looms; those lised in this study were $21 / 2$ inch in thickness.

Table I lists the materials irradiated in this study, all of which were obtained courtesy of McDonne 11 Douglas Astronautics Company-East. Cloth samples 1-4 from the first (lowest fluence) irradiation were returned to them for degassing measurements following postirradiation examination at PNL. 
TABLE I. Materials Description(a)

CLOTHS:

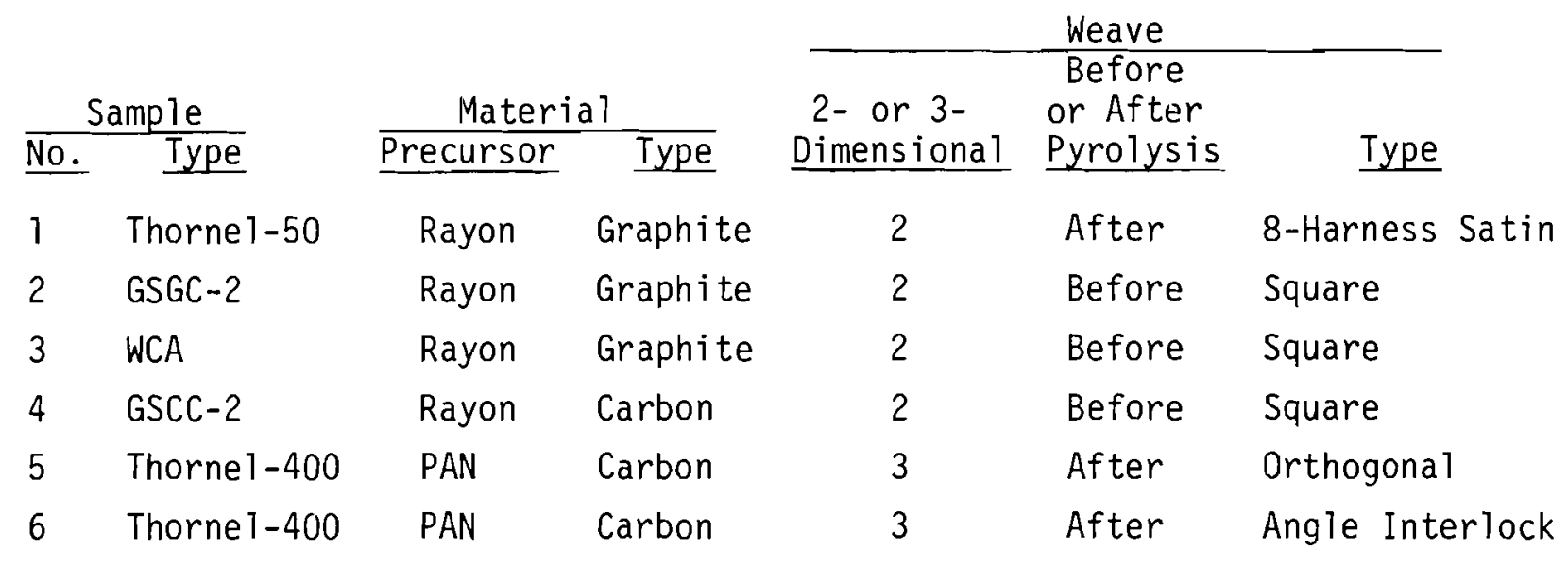

\section{FIBERS:}

\begin{tabular}{|c|c|c|c|c|}
\hline \multicolumn{2}{|c|}{ Sample } & \multicolumn{2}{|c|}{ Material } & \multirow{2}{*}{$\begin{array}{c}\text { Crystal } \\
\text { Orientation }\end{array}$} \\
\hline No. & Type & Precursor & Type & \\
\hline 1 & $\begin{array}{l}\text { Thornel-50S } \\
(\text { WYH-140 } 1 / 2 \text { ) }\end{array}$ & Rayon & Graphite & High \\
\hline 2 & GSGY-2 & Rayon & Graphite & Low \\
\hline 3 & WYB $-85 \quad 1 / 2$ & Rayon & Graphite & Low \\
\hline 4 & GSCY - 2 & Rayon & Carbon & Low \\
\hline 5 & $\begin{array}{l}\text { Thorne I-400 } \\
(\text { WYM-30 } 1 / 0)\end{array}$ & PAN & Carbon & Moderate \\
\hline 6 & Type A & PAN & Carbon & Low \\
\hline 7 & VSA-11 & Pitch & Graphite & High \\
\hline 8 & $\begin{array}{l}\text { Thorne 1-75S } \\
\text { (WYJ-160 } 1 / 2)\end{array}$ & Rayon & Graphite & Very High \\
\hline 9 & $C-20$ & Rayon & Carbon & Low \\
\hline 10 & $\begin{array}{l}\text { Thorne 1-300 } \\
(\text { WYP-30 } 1 / 0)\end{array}$ & PAN & Carbon & Moderate \\
\hline 11 & VYB $-70 \quad 1 / 2$ & Rayon & Carbon & Low \\
\hline
\end{tabular}

(a) Fibers in cloth samples 1-6 are the same as fiber samples 1-5 with the exception of the \#3 samples where the cloths and fibers are similar but not identical. 
Due to limited reactor space, samples were 1 imited to $\sim 1 / 2$ inch diameter. Therefore, 2-D cloth discs $21 / 2$ inch in diameter were cut out, and the edges of these were bound lightly with a carbonaceous cement to minimize fraying. This technique didn't work well for the 3-D cloth samples. Therefore, $1 / 2$ inch diameter cylinders of the 3-D cloths were cut out using a tool similar to a cork borer, and the samples were pushed directly out of the tool into graphite cylindrical sample holders. In addition to the cloth samples, portions of 11 different types (only 9 types were placed in the first capsule) of individual yarns containing up to 200 fibers each were mounted, like spokes on a wheel, cn carbon discs.

Pre-irradiation characterization of the cloth samples consisted of a series of micrographs at various magnifications taken both optically and with a scanning electron microscope (SEM). The intent of these pictures was to allow both a visual comparison before and after irradiation, as well as a means to determine dimensional changes. In addition to the pictures, preirradiation clensity and BET surface area measurements were made on the 2-D cloths.

Pre-irridiation characterization of the fiber samples again consisted of a series of micrographs at various magnifications. In addition, small carbon dots were deposited on individual fibers to serve as fudicial marks for length-change measurements. The dots were deposited with the SEM as described by Bunne11. (19)

A serie:s of samples such as described above was placed into each of three different subassemblies which in turn were placed in three different Hanford Engineering Development Laboratory capsules for irradiation in EBR-II. Since this was a piggyback experiment, irradiation temperatures could not be tailored. Furthermore, the capsules were uninstrumented and temperatures had to be calculated. Internal heat generation in these subassemblie:s was quite low; therefore, the samples ran only a few degrees above the sodium coolant temperature in the reactor which was known to be $425 \pm 25^{\circ} \mathrm{C}$. Thus, sample temperatures were calculated to be in the range $400-500^{\circ} \mathrm{C}$. The fluences of $3.5,7.3$, and $10 \times 10^{21} \mathrm{~cm}^{-2}$ were determined, (20) 
using dosimetry previously done for a similar position in EBR-II, and apply to the individual fibers and 2-D cloth samples. The 3-D cloth samples experienced fluences about $17 \%$ higher in each capsule. As noted earlier, all fluences are quoted in terms of "Equivalent Fission Fluence for Damage in Graphite."(14) Based on the current atomic displacement cross sections as a function of neutron energy, a fluence of $1.01 \times 10^{2} \mathrm{~cm}^{-2}$ produces one displacement per atom (dpa) in graphite independent of the neutron energy spectrum. $(15,21)$ Atomic displacement cross sections used at present are derived from theoretical models. An experiment designed to verify (or adjust) the theoretical cross sections for neutron energies up to $\sim 15 \mathrm{MeV}$ is nearing completion and the results will be published shortly. (22)

\section{RESULTS AND DISCUSSION}

\section{FIBER AXIAL LENGTH CHANGES}

Fiber length changes were determined only on the 2-D cloth samples using low-magnification pictures such as those shown in Figures $6,9,12$ and 15. Two methods were used: 1) length measurements were made wherever both ends of a given yarn were clearly visible both before and after irradiation, and 2) the areas of the cloths were measured with a Quantamet-720 quantitative image analyzer, and lengths (cloth diameters) were calculated. Only the first method was used on samples from the first capsule. Length changes determined by the first method were different in the orthogonal directions " $W$ " and " $F$ ". Careful examination of Figures 6, 9, 12 and 15 reveals that there are more yarns perpendicular to the "W" direction than there are perpendicular to the "F" direction. Table II shows the length changes were generally greater in the "F" direction. Perhaps this is due to greater frictional restraint in the " $W$ " direction as the cloths shrink and close up the gaps between yarns. Gap closure would aiso occur sooner in the "W" direction. If this hypothesis is valid, the "F" values in Table II may be more indicative of restraint-free shrinkage and, where avai1able, these are the values that are plotted in Figure 2. Failure to recognize the shrinkage difference in the two directions led to results reported earlier for samples from the first capsule that are different from those given here. The "A" values in Table II lie closer to the "W" than the "F" values. Seemingly 
TABLE II. Axial Shrinkages of Fibers in Graphite and Carbon Cloths Irradiated at $470^{\circ} \mathrm{C}^{(\mathrm{a}, \mathrm{b})}$

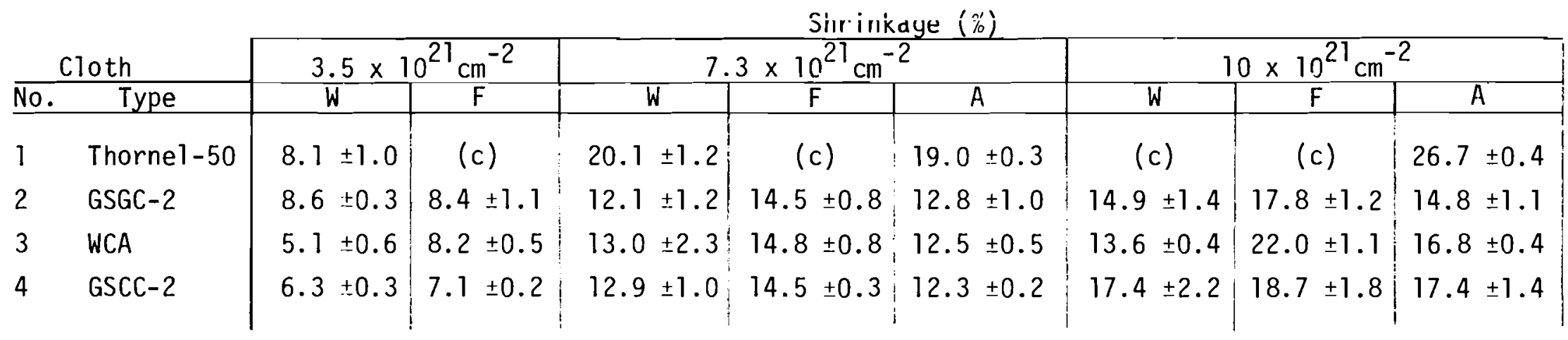

(a) W and $F$ values are for the two orthogonal directions in the cloth; $A$ values are taken from area measurements. See text for additional explanations.

(b) Uncertainties listed are two times the standard deviations of the percentage differences between irradiated and unirradiated lengths.

(c) A11 yarn ends in this direction were obscured thereby preventing length measurements; see text. 
they should lie in between and because they do not, probably imply a slight bias in one measuring method or the other. The direct measurements, " $W$ " and "F", seem less subject to error than the area measurements, "A". Finally, the length changes measured by either method could be partially attributed to increased fiber curvature but, with the exception of Thorne1-50 which appears to have become somewhat kinky, that doesn't appear to be the case.

The fudicial marks placed on the fiber samples with the SEM as described earlier apparently were totally destroyed during irradiation thereby precluding any length measurements on the fiber samples.

All of the axial dimensional changes observed, as well as at least some of the radial dimensional changes discussed below, are quite large when compared with changes observed in typical nuclear graphites $(7,23,24)$ under similar conditions as shown in Figure 3 . This figure shows dimensionalchange data as a function of fluence for a typical nuclear graphite at a variety of temperatures merely to show the effect fluence and temperature can have. These data should not be construed to imply that cloth dimensional changes will vary with temperature and fluence in a similar fashion. A complete picture of the irradiation behavior of cloth can only be determined through additional irradiation tests.

\section{FIBER DIAHETER CHANGES}

The fiber samples were remounted after irradiation so that they could be viewed in cross section for the purpose of looking at both fractured and polished end surfaces. The latter were used to determine changes in cross sectional areas. The fibers proved to be very difficult to handle following irradiation, and only five different types from the first capsule were successfully remounted. Fibers from the second capsule were lost during capsule disassembly. All eleven types of fibers from the third capsule were successfully remounted.

A typical example of polished cross-sections of rayon-based fibers is shown in Figure 23 and of PAN-based fibers in Figure 24 . The variation in cross-sectional area from one fiber to another is typical of al1 11 types of fibers. A second observation is typical of all types of fibers except 
the one shown in Figure 22 (to be discussed later). That is, irradiation has caused 'no noticeable change in appearance such as shape, cracks, pores, etc.

Cross sectional areas of 15 to 90 unirradiated fibers of each type were measured and compared with areas measured on 3 to 35 irradiated fibers. In each case, the cross sectional areas were converted to circles of equivalent areas, and Table III lists changes in mean equivalent fiber diameter. Differences between the diameter changes listed here for samples from the first capsule $\left(3.5 \times 10^{21} \mathrm{~cm}^{-2}\right)$ and those reported earlier $(17)$ are due to a new set of micrographs taken with much sharper definition of the fiber edges which should produce more reliable data. The uncertainties listed are based on the variance of the different sample populations. Although the listed uncertainties are rather large, measurements on different populations of the same fiber type indicated that the real uncertainties might be even larger. To get a better feel for this, three different samples of each of three different types of unirradiated fibers were measured. The results shown in Table IV reveal differences at the 95\% confidence level of up to $28 \%$ in mean equivalent diameter between different populations of the same fitier type. Thus, it can be stated with certainty only that diameter chonges occurred at the highest irradiation level for fiber types $1,7,10$ and 11. The internal cracks, or holes in fiber No. 7 (type VSA-11) shown in Fiçure 22b were discounted for the purpose of determining its diameter change.

Fiber No. 8 (Thornel-75S) is similar to fiber No. 1 (Thornel-50S) except that it is even more highly oriented. Thus, it seems that its radial swelling should have been at least as large. The fact that only one Thornel-75S fiber was successfully remounted for examination makes it impossible to determine whether or not this was true.

The only previous work where a direct comparison with the present data is possible is due to Peggs $(16)$ who found that Thornel-50S fibers swelled $\checkmark 50 \%$ in the radial direction after irradiating to $21.5 \times 10^{21} \mathrm{~cm}^{-2}$ at $400-700^{\circ} \mathrm{C}$. For both Peggs' and the present data to be correct, the fibers would first have to swell, then shrink back to about normal size, and then swell again. 
TABLE III. Mean Equivalent Diameter Changes of Irradiated Fibers

\begin{tabular}{|c|c|c|c|}
\hline & Fiber & Diameter & ange $(\%)^{(a)}$ \\
\hline No. & Type & $3.5 \times 10^{27} \mathrm{~cm}^{-2}$ & $10 \times 10^{21} \mathrm{~cm}^{-2}$ \\
\hline 1 & $\begin{array}{l}\text { Thornel-50S } \\
\text { (WYH-140 } 1 / 2)\end{array}$ & $-3.1 \pm 3.2$ & $+30.6 \pm 2.3$ \\
\hline 2 & GSGY-2 & $-5.5 \pm 2.4$ & $-3.6 \pm 3.6$ \\
\hline 3 & WYB-85 $1 / 2$ & $-0.4 \pm 2.4$ & $-6.7 \pm 6.6$ \\
\hline 4 & GSCY-2 & & $-6.8 \pm 1.9$ \\
\hline 5 & $\begin{array}{l}\text { Thorne]-400 } \\
\text { (WYM-30 } 1 / 0 \text { ) }\end{array}$ & & $-4.2 \pm 2.8$ \\
\hline 6 & Type A & $-5.5 \pm 2.3$ & $+0.3 \pm 3.2$ \\
\hline 7 & VSA-11 & & $+32.9 \pm 8.0$ \\
\hline 8 & $\begin{array}{l}\text { Thornel-75S } \\
\text { (WYJ-160 } 1 / 2 \text { ) }\end{array}$ & & $-5.0^{(b)}$ \\
\hline 9 & $c-20$ & $-0.7 \pm 2.2$ & $-4.0 \pm 1.4$ \\
\hline 10 & $\begin{array}{l}\text { Thornel-300 } \\
\text { (WYP-30 } 1 / 0 \text { ) }\end{array}$ & & $-15.8 \pm 2.9$ \\
\hline 11 & VYB-70 $1 / 2$ & & $-19.3 \pm 4.1$ \\
\hline
\end{tabular}

\footnotetext{
(a) Uncertainties listed are two times the standard deviations of the percentage difference between irradiated and unirradiated mean diameters. See text for discussion of additional uncertainties.

(b) Only one irradiated fiber measured.
} 
TABLE IV. Mean Equivalent Diameters of Selected Unirradiated Fibers

\begin{tabular}{|c|c|c|c|c|}
\hline \multicolumn{2}{|c|}{ Fiber } & $\begin{array}{l}\text { No. of Fibers } \\
\text { Measured }\end{array}$ & $\begin{array}{l}\text { Mean Equivalent } \\
\text { Diameter, } \mu \mathrm{m}\end{array}$ & $\begin{array}{c}\text { Standard Deviation } \\
\text { Of Mean }\end{array}$ \\
\hline \multirow[t]{3}{*}{1} & \multirow{3}{*}{$\begin{array}{l}\text { Thorne1-50S } \\
\text { (WYH-140 } 1 / 2 \text { ) }\end{array}$} & 78 & 6.43 & 0.03 \\
\hline & & 68 & 6.49 & 0.03 \\
\hline & & 87 & 6.33 & 0.02 \\
\hline \multirow[t]{3}{*}{3} & \multirow[t]{3}{*}{ WYB- $85 \quad 1 / 2$} & 57 & 8.35 & 0.06 \\
\hline & & 49 & 8.09 & 0.08 \\
\hline & & 36 & 8.77 & 0.08 \\
\hline \multirow[t]{3}{*}{8} & \multirow{3}{*}{$\begin{array}{l}\text { Thorne1-75S } \\
\text { (WYil-160 } 1 / 2 \text { ) }\end{array}$} & 55 & 8.93 & 0.05 \\
\hline & & 51 & 9.38 & 0.04 \\
\hline & & 61 & 9.01 & 0.04 \\
\hline
\end{tabular}

Such behavior, although with considerably smaller total changes, has been observed $^{(25)}$ in one type of graphite $(A X Z-5 Q 1)$ before. Additional irradiations would be required to substantiate such behavior for the Thorne1-50S fibers, however. Sma11 temperature differences between the present irradiation and that of Peggs are possible but seem unlikely to be responsible for the apparently different results.

\section{DENSITY}

Densities of the four types of 2-D cloths were measured by liquid immersion in toluene, and the results are shown in Figure 4 . Reproducibility of the measurements was $\pm 27 \%$. The density increase of the Thornel-50 was much smaller than for the other three types which is a reflection of the large radial swelling of the Thornel-50 fibers compared with no swelling or even shrinkage in the radial direction of the others. 


\section{SURFACE AREA}

Figure 5 shows BET surface areas measured with krypton. In general, only one measurement per sample was made but in the few instances of duplicate measurements, reproducibility of $\pm \sim 10 \%$ was found. The surface area converged to similar values at the intermediate fluence and then appear to have diverged slightly at the highest fluence.

With the exception of WCA, the surface area changes of the cloths exceed by wide margins the changes calculated (assuming the fibers to be cylindrical in shape) from radial and axial changes in fiber dimensions. Evidently some very fine porosity not visible at magnifications as high as $30,000 x$ has been eliminated.

Atomic hydrogen sticking probabilities were measured for cloths from the first capsule $\left(3.5 \times 10^{21} \mathrm{~cm}^{-2}\right)$ by Fivel et al. (26) and compared with the sticking probabilities of unirradiated cloths. In all cases for temperatures $\leq 800^{\circ} \mathrm{C}$, the irradiated cloths had higher sticking probabilities. This is not a surprising result if sticking probabilities are higher at edge sites and defects than at basal plane surfaces, which seems likely, because irradiation increases the number of defects.

The method used to measure sticking probabilities $(26,27)$ yields valid engineering numbers. However, it is based on the assumption that each atom strikes the carbon surface only once, and sticking probability is taken to be simply the number of atoms absorbed divided by the number that strike the surface. Actually this is an oversimplication because, on an atomic scale, the surface must be quite irregular and many hydrogen atoms are reflected at angles such that they strike the surface more than once. Thus, what might be called a "true" sticking probability (that is, the sticking probability per collision) is not determined. Measured sticking probabilities would be lower for less irregular surfaces given equal true sticking probabilities.

Surface areas of the cloths decreased during irradiation. In some sense, therefore, the surfaces must have become smoother and the measured sticking probabilities would have decreased if the true sticking probabilities had remained unchanged. The fact that the measured sticking probabilities increased means simply that the true sticking probabilities increased by an even greater amount. 


\section{MICROGRAPHIC EXAMINATION}

Figures 6-17 are micrographs of the four types of 2-D cloths. In each case, micrographs $a$ and $b$ are of the same area of the same specimen while micrographs $c$ and $d$ are different specimens than $a$ and $b$ and also different from each other. The small, generally shiny, dots found on micrographs b-d of Figures $6,9,12$, and 15 are a carbonaceous cement placed on the cloths for orientation markers after micrographs of the unirradiated cloths had already been taken.

Figures 6 and 7 show that Thornel-50 cloth deteriorated during irradiation and the individual fibers became somewhat kinky. At the magnification shown in Figure 8, the Thornel-50 fibers appear virtually unchanged by irradiation. The cause of the fuzzy appearance of the fibers in Figures $8 \mathrm{c}, 11 \mathrm{c}$, and $17 \mathrm{c}$ is unknown, but is not believed to be a property of the fibers. This phenomenon will be discussed later.

Figures 9-17 show that the other three types of 2-D cloths changed little during irradiation except for a general tightening up of the weave caused by axial shrinkages of the fibers. Figures $11 \mathrm{a}$ and $b$ show a fiber with a flaw (crack) and even this was unchanged by irradiation.

Figures 18 and 19 are micrographs of the two types of 3-D cloths. Again, micrographs $a$ and $b$ are of the same specimen while micrographs $c$ and $d$ are different specimens than $a$ and $b$ and also different from each other. In contrast to the 2-D cloths, the 3-D cloths have literally torn themselves apart. In the $b$ micrographs, one can see yarn ends that are beginning to pull out, yarn loops that are tightening, overall tightening and shrinking, and a good deal of fraying. The latter may be due to fibers breaking, perhaps because of increased curvature or high tensile stresses caused by restrained shrinkage. Alternatively, some of the fibers may simply be pulling out so that ends are visible after irradiation but not before. Micrographs $c$ and $d$ of both figures can no longer be matched with the micrographs of these specimens taken before irradiation (not shown). The processes described above as having taken place during the first irradiation have continued to the point of nearly total destruction of the specimens in the second and third irradiations. 
No direct measurements were made on the 3-D cloths, so it cannot be stated with certainty that the fibers in these materials have shrunk as dramatically as have those in the 2-D cloths, but that seems likely to be the case. If so, it is apparent that the 2-D cloths are able to accommodate the shrinkage that has taken place in the axial direction of the fibers whereas the 3-D cloths are not. It is easy to rationalize this difference in behavior. There is little in the 2-D cloths to restrain the fibers from shrinking or to cause problems when they do. With the 3-D materials, on the other hand, it can be seen in Figure 1 that axial shrinkage of the $Z$ yarns will be resisted by friction. Furthermore, if axial shrinkages exceed radial shrinkages, axial shrinkage of the $Z$ yarns will be restrained for this reason also. In the small samples used in this study, it is relatively easy for some of the yarns to pull out, but in a large piece of cloth, fiber breakage appears likely to occur.

Micrographs (not shown) of the 3-D cloths were taken at high magnification (up to 10,000X) only after the first irradiation. No difference was observed between the irradiated and unirradiated cloths. Micrographs (not shown) at high magnification were also taken before irradiation and after the first and third irradiations of the same type of fibers (Thorne1-400) used in the 3-D cloths. No differences due to irradiation were found. Thus, the deterioration of the 3-D cloths observed at low magnification (Figures 18 and 19) must be due to axial fiber shrinkage although this was not confirmed by direct measurements.

Figures 20 and 21 show fractured ends of fibers. The b micrographs in both figures show as-irradiated fiber ends. The knobby appearance is typical of all 11 types of fibers. Microgaphs $c$ and $d$ show fiber ends fractured after irradiation and after the $b$ micrographs were taken. Many of the VSA-11 fibers split in a manner which left a void in the center of the fiber as shown in Figure 20. The crystallites in this type of fiber are quite well oriented, but also oriented differently than in any of the other types of fibers. They tend to lie with their basal planes parallel to the radial direction of the fibers. Since irradiation causes graphite crystals to shrink and swell respectively in directions parallel and perpendicular to the basal planes, the fibers would tend to shrink in the 
radial direction and swell in the circumferential direction. Thus, the surface wolld be placed in compression and the interior in tension leading to the types of cracks shown. The fiber ends shown in Figure 21 , which were fractured after irradiation, are typical of all the other 10 types of fibers. That is, little difference between irradiated and unirradiated fibers can be seen.

Figures 22-24 show polished fiber ends. These micrographs are typical of the one:s used to measure the fiber diameter changes listed in Table III. Fibers in Figures 23 and 24 are typical of rayon-based and PAN-based fibers, respectively. That is, the former are irregular in shape whereas the latter are more nearly round. Both types exhibited little change due to irradiation in the sense that there is no obvious shape change or crack or pore generation, etc. This observation is typical of 10 of the fiber types. Only the VSA-11 fibers shown in Figure 22 changed during irradiation in any regard other than size.

\section{THE FUZZY FIBER PHENOMENON}

Earlier, the fuzzy appearance of fibers in Figures 8c, 11c, and 17c was briefly mentioned. It was first observed on all nine types of fibers from the first irrajiation capsule. Within any given type of fiber, some fibers were fuzzy while others were not. Fibers with fuzz were examined at a variety of angles, inzluding stereo pairs, and magnifications. Efforts were made to remove the fuzz by ultrasonic cleaning in acetone, but it didn't budge in the slightest. The energy dispersive x-ray fluorescence capability of the SEM was used to try to identify the elemental composition of the fuzz with negative results. This system does not detect elements with atomic numbers less than 11 and, therefore, would not detect carbon. Every impression was given that surface layers had peeled from the fibers onionskin fashion; however, there were some problems with this idea. None of the cloth samples had the slightest hint of fuzz even though they were composed of some of the same types of fibers. Furthermore, as mentioned above, within a bundle of fibers, solne fibers didn't have the fuzz. 
Most of the fibers had been coated during manufacturer with either a polyvinyl alcohol or UC-307 epoxy-based sizing. Only one of the cloths, Thorne1-50, had been sized. Despite the fact that the Thorne1-50 cloth had no fuzz, the sizing seemed to be a possible source of the fuzz on the fibers; perhaps the sizing was peeling off. However, the sizing should have been totally removed by heating in vacuum to $\sim 700^{\circ} \mathrm{C}$, and all of the fibers had been heated in vacuum to $\sim 1000^{\circ} \mathrm{C}$ after they were mounted on the glassy carbon disc used to hold them during irradiation. In addition, a11 samples, both fibers and cloths, were degassed at $\sim 700^{\circ} \mathrm{C}$ in vacuum prior to welding the irradiation capsules shut.

Next, the glassy carbon disc that the fibers were mounted on was examined with the SEM at high magnification. A very similar fuzzy material was observed in abundance. Perhaps thin layers of carbon had peeled from the glassy carbon disc and become attached very tenaciously to the fibers. The cloths were contained in nuclear grade polycrystalline graphite holders and they had no fuzz.

But the problem was not entirely solved. Upon examination of specimens from the second capsule, fuzz was found on three of the four types of 2-D cloths (Figures 8c, 11c, and 17c). As mentioned earlier, the fiber specimens from the second capsule were lost during capsule disassembly. Could fuzz from the glassy carbon disc containing the fibers have migrated into the graphite holders (not hermetically sealed) containing the cloths? If so, why did it not happen in the first and third capsules? The answer is unknown.

All eleven types of fibers from the third capsule had the fuzz but none of the cloth samples. The appearance of the fuzz was, in all respects, the same as described for specimens from the first capsule.

Although it appears that the fuzz is not a property of the fibers or the sizing thereon, this has not been established beyond doubt. The glassy carbon mounting discs seem the most likely source of the fuzz but, again, this was not proven. 


\section{CONCLUSIONS}

Three cf the four types of 2-D cloth samples irradiated in this study have remained intact even though the fibers have undergone axial shrinkages of 18 to $27 \%$. If additional irradiation tests show that they remain intact at higher fluences and temperatures, their use in fusion reactor applications may be possitle providing the large shrinkage can be accommodated through curtain or reactor design. Other changes observed for the 2-D cloths were large density increases and all but one had a large decrease in surface area. The 3-D cloths, on the other hand, have deteriorated. Thus, the development cif 3-D weaves that are able to accommodate large axial fiber shrinkages appears necessary before their use can be considered.

At least three different basic types of rayon-based fibers were represented in the 2-D cloths where large axial shrinkages were found. Such large shrinkages thus seem likely to be characteristic of rayon-based fibers in gerieral. Irradiation-induced length-change data are needed on PAN and pitch-based fibers to determine if their shrinkages are also large.

Radial dimensional changes of 11 different types of fibers varied from shrinkacle of 19\% through almost no change to swelling of $33 \%$. It is not clear whot effects radial dimensional changes might have on the general performance of cloths.

\section{ACKNOWLEDGMENT}

The permission and assistance of J. A. Basmajian and others at the Hanford Engireering Development Laboratory, Richland, Washington, for including the samples used in this study in their irradiation capsules is gratefully acknowledged. Thanks are also due G. P. Lang of McDonnell Douglas Astrcinautics Company-East for furnishing the samples and to L. R. Bunne11, G. Wilson, and F. D. Hobbs for assistance in the preparation and postirraciation examination of samples. 


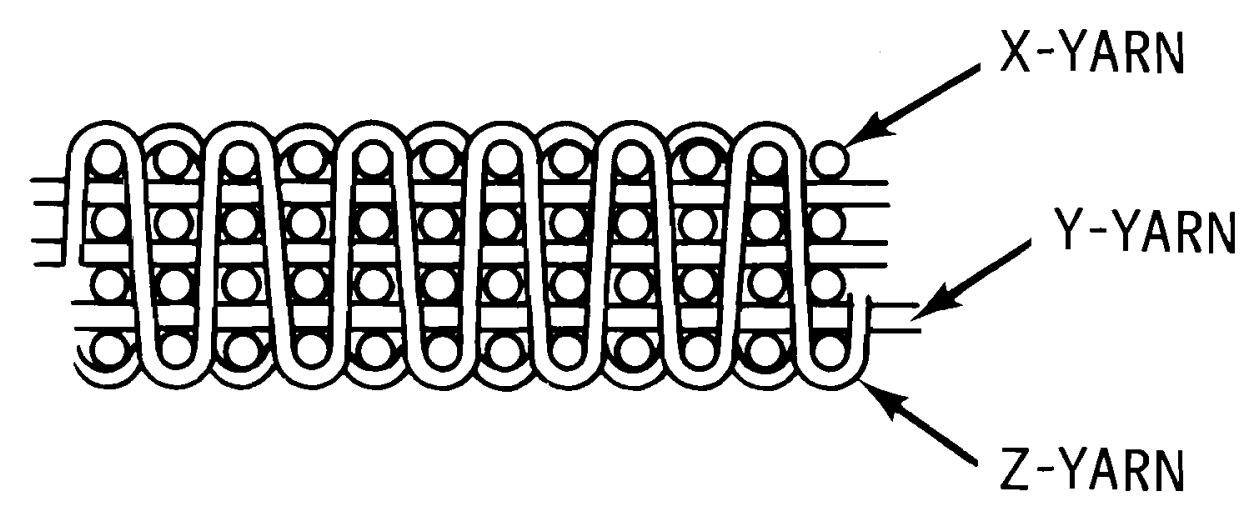

Orthogonal Weave

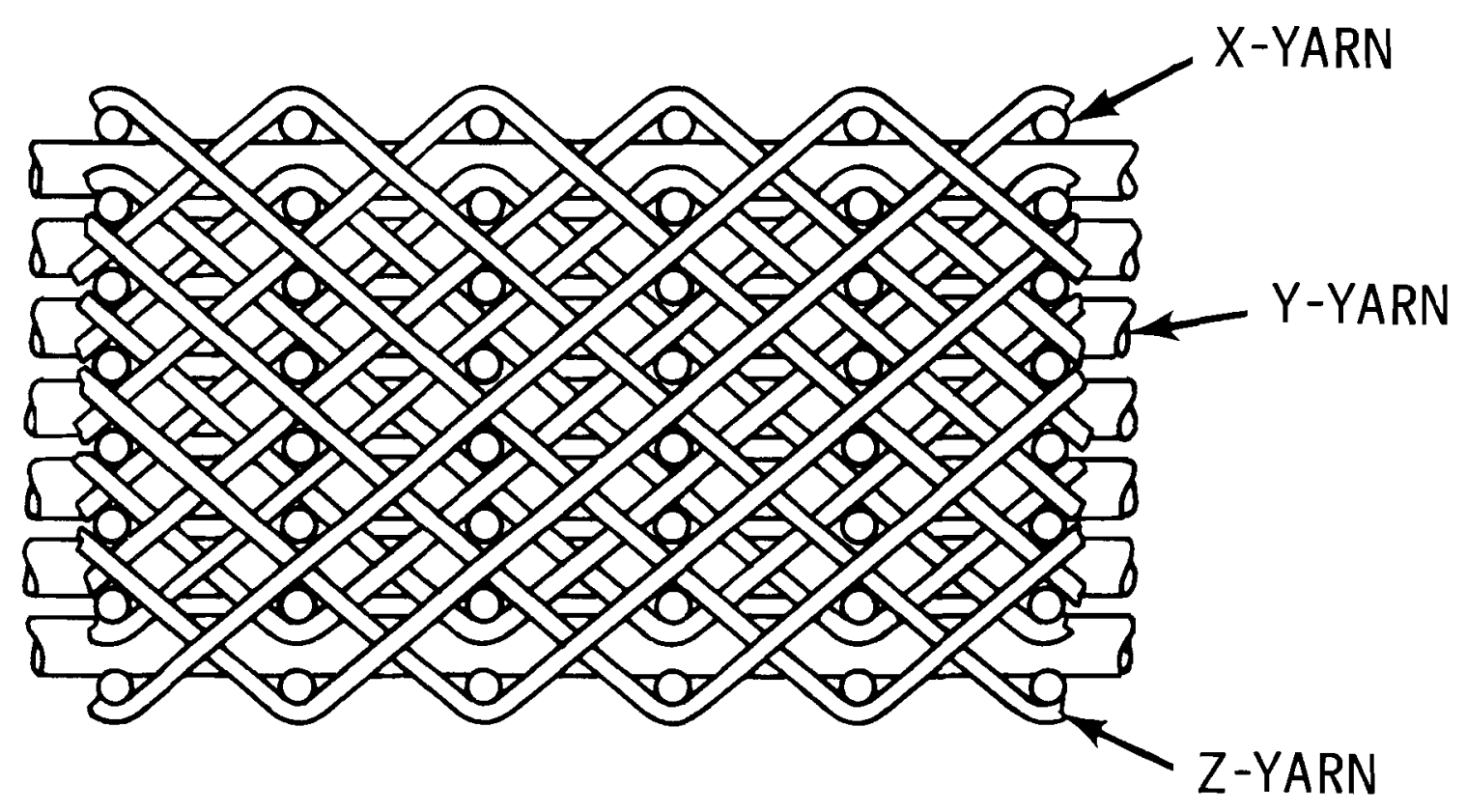

Angle Interlock Weave

FIGURE 1. Schematic diagram of 3-dimensional weaving patterns. 


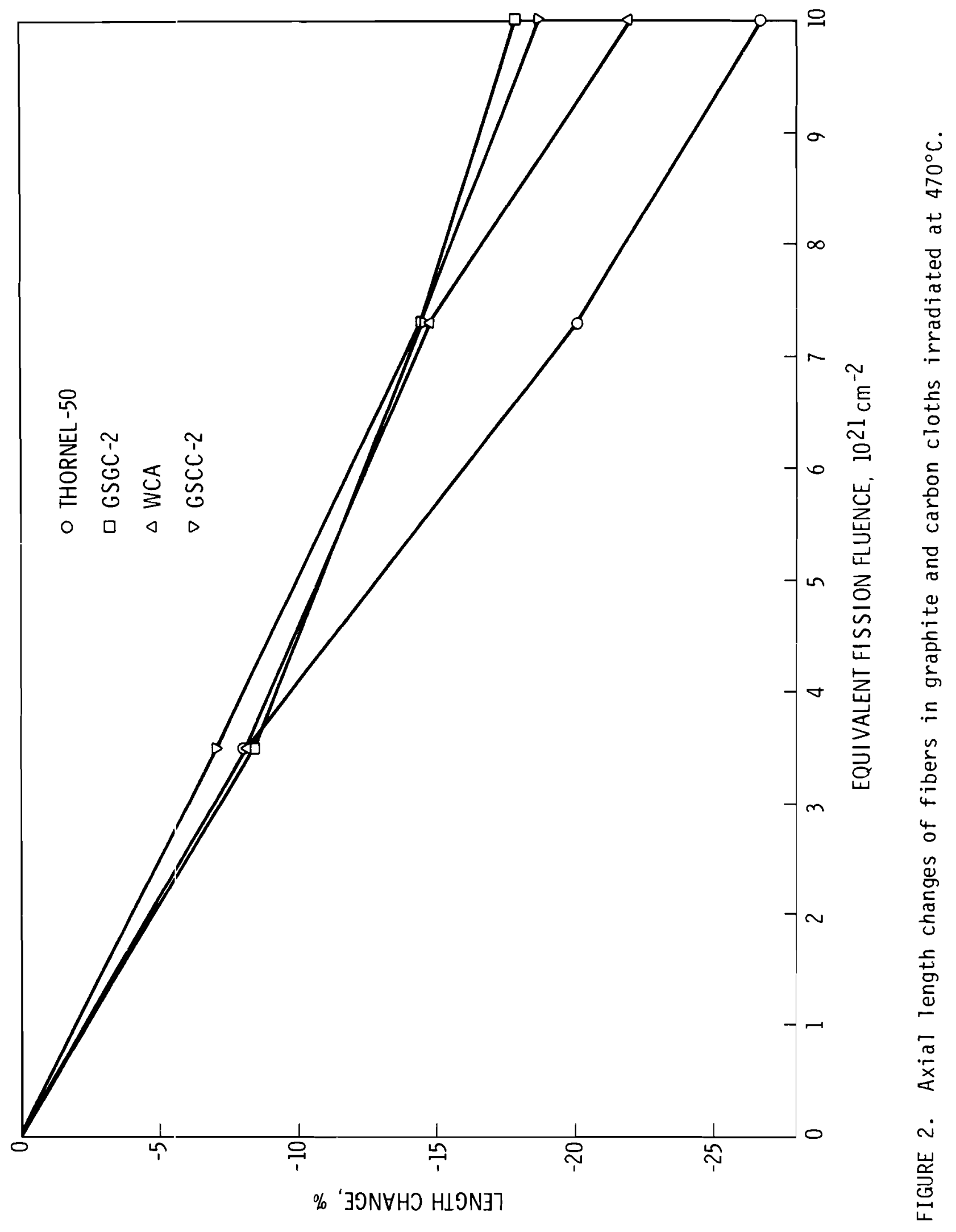




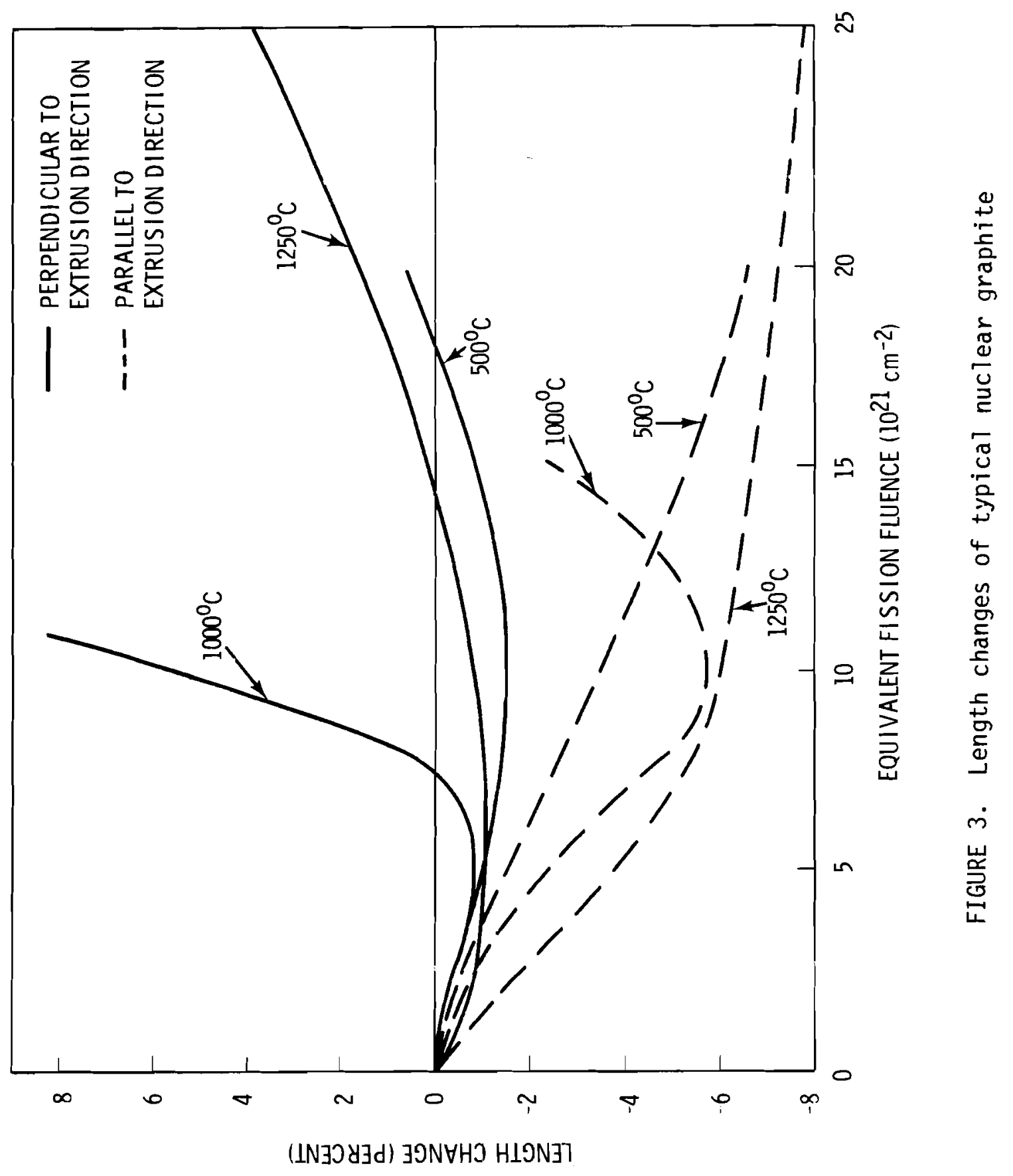




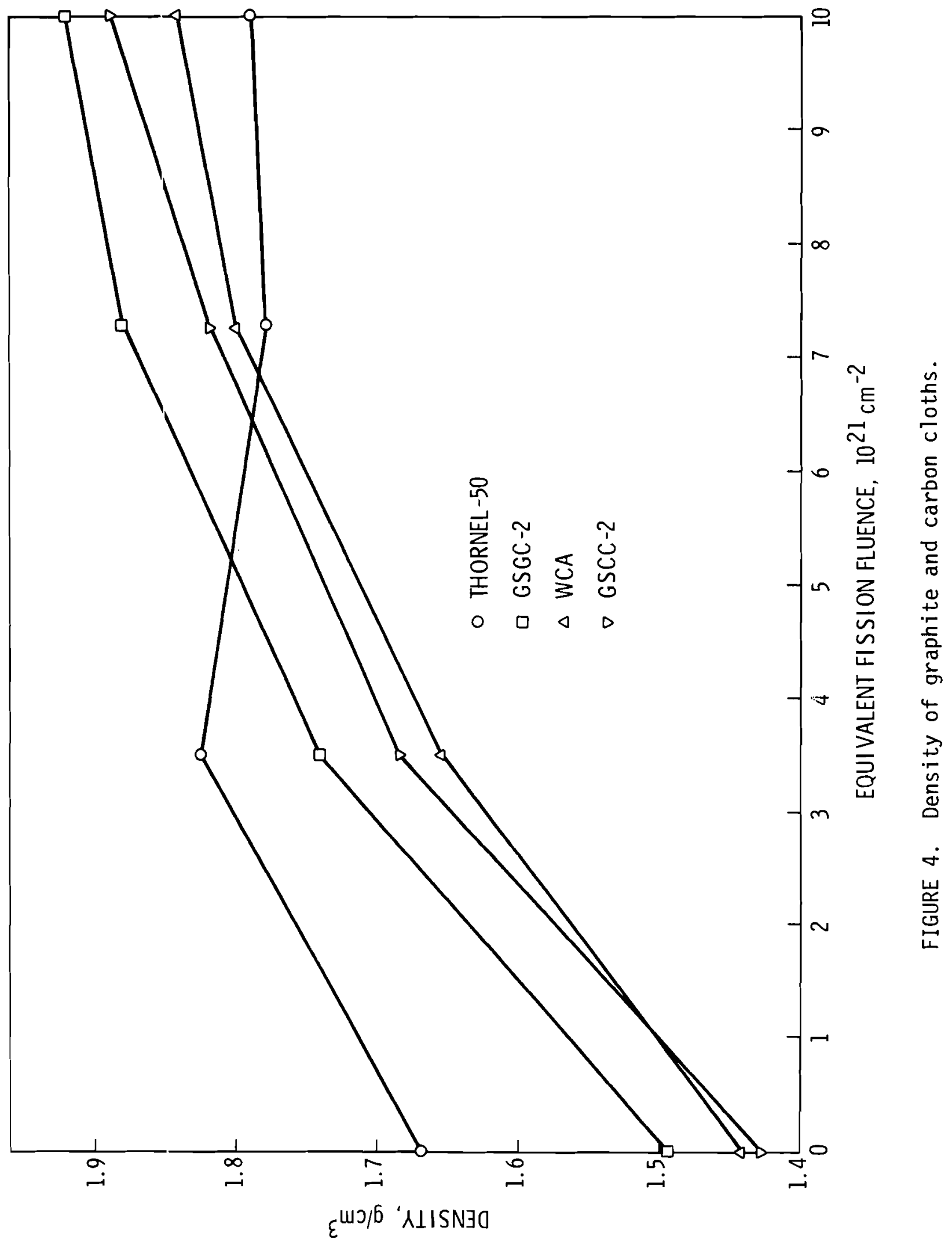




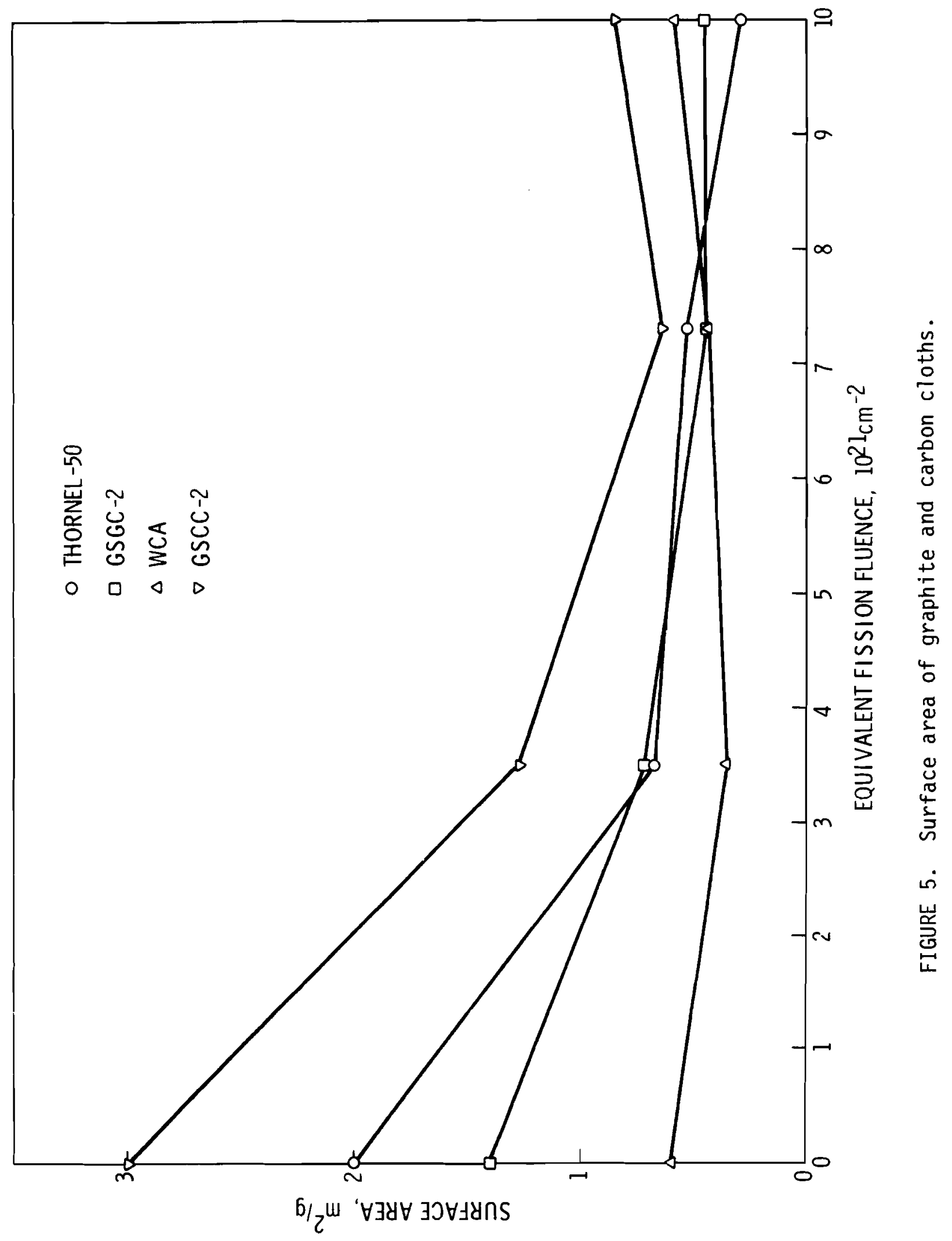



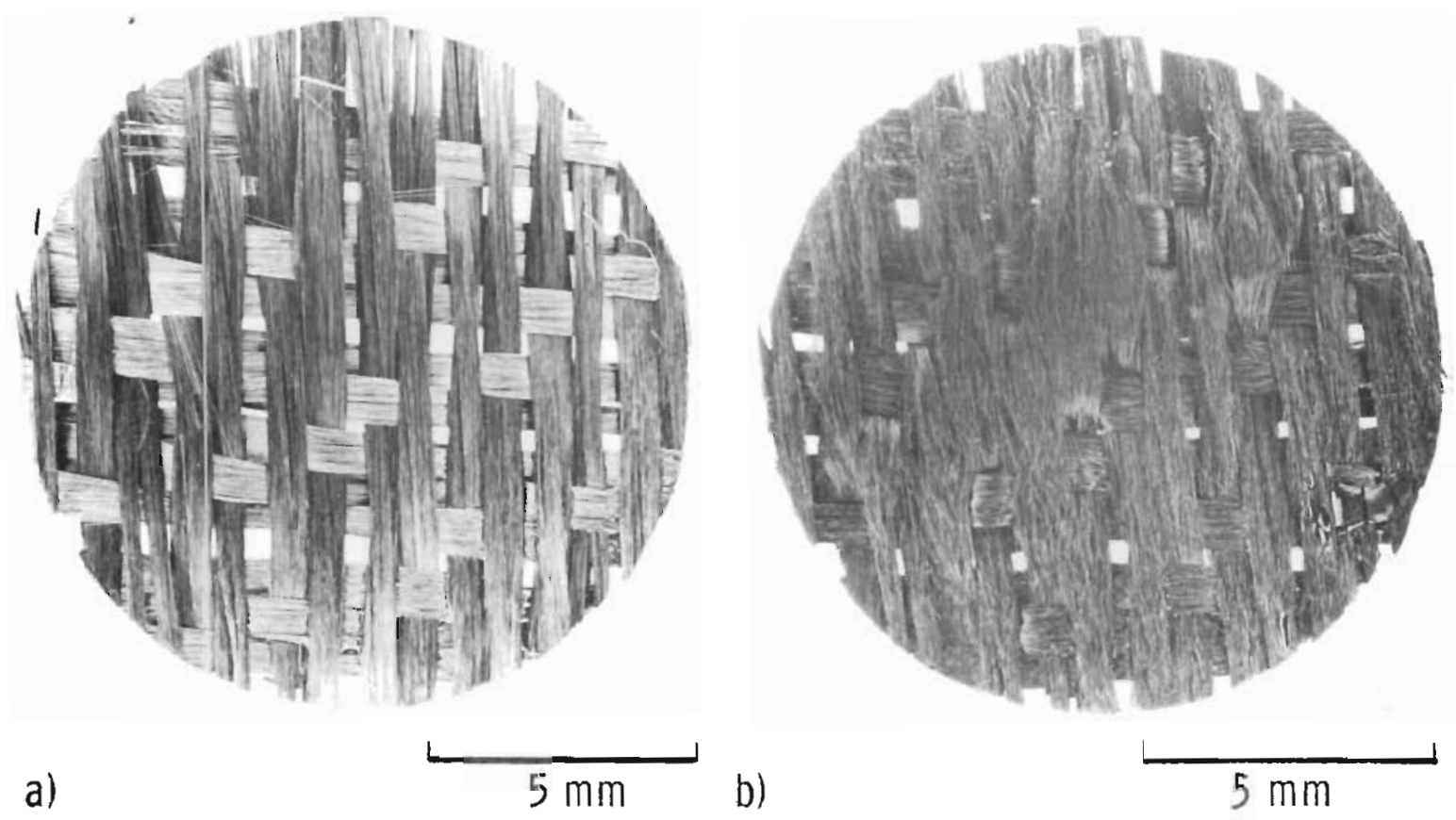

a)

$5 \mathrm{~mm} \quad$ b)
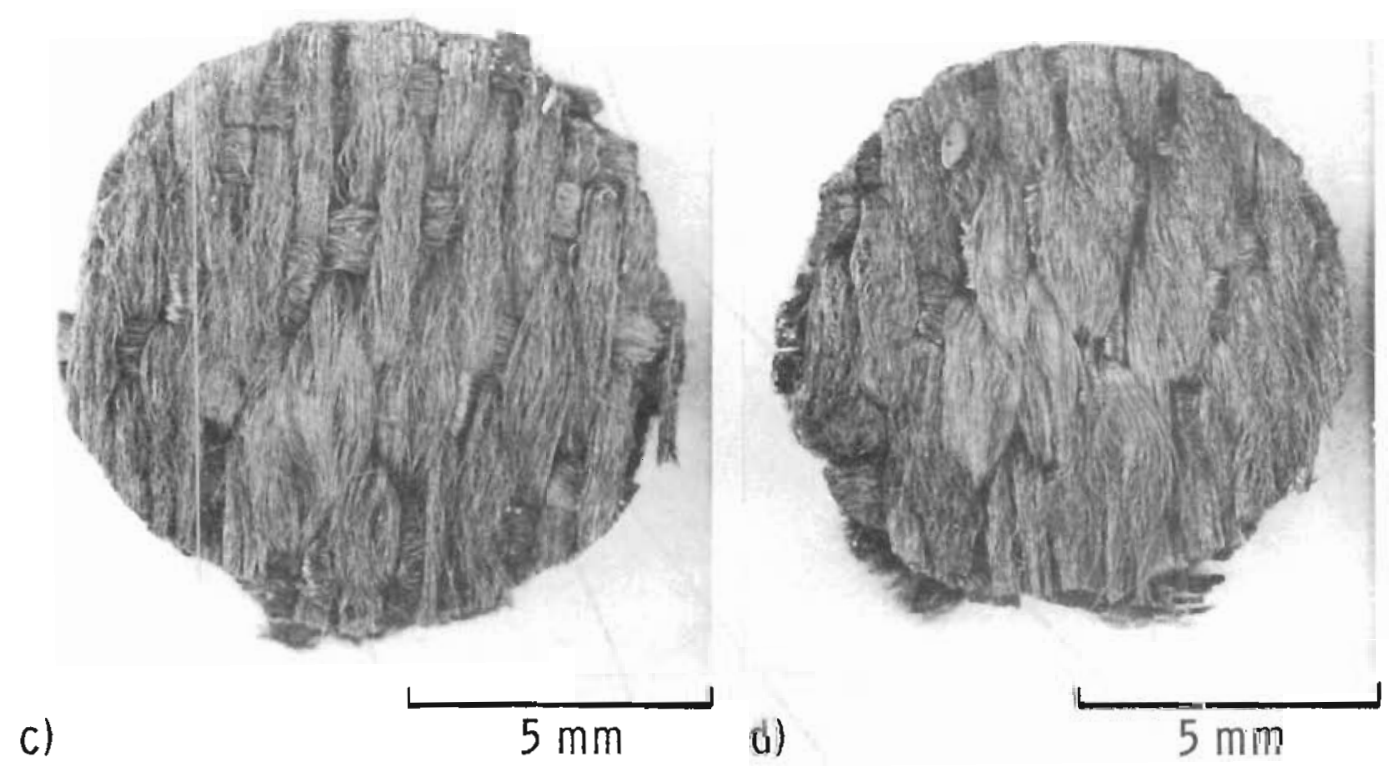

FIGURE 6. Thorne1-50 Graphite C1oth; a) Unirradiated, b) $3.5 \times 10^{21} \mathrm{~cm}^{-2}$, c) $7.3 \times 10^{21} \mathrm{~cm}^{-2}$, d) $10 \times 10^{21} \mathrm{~cm}^{-2}$ 

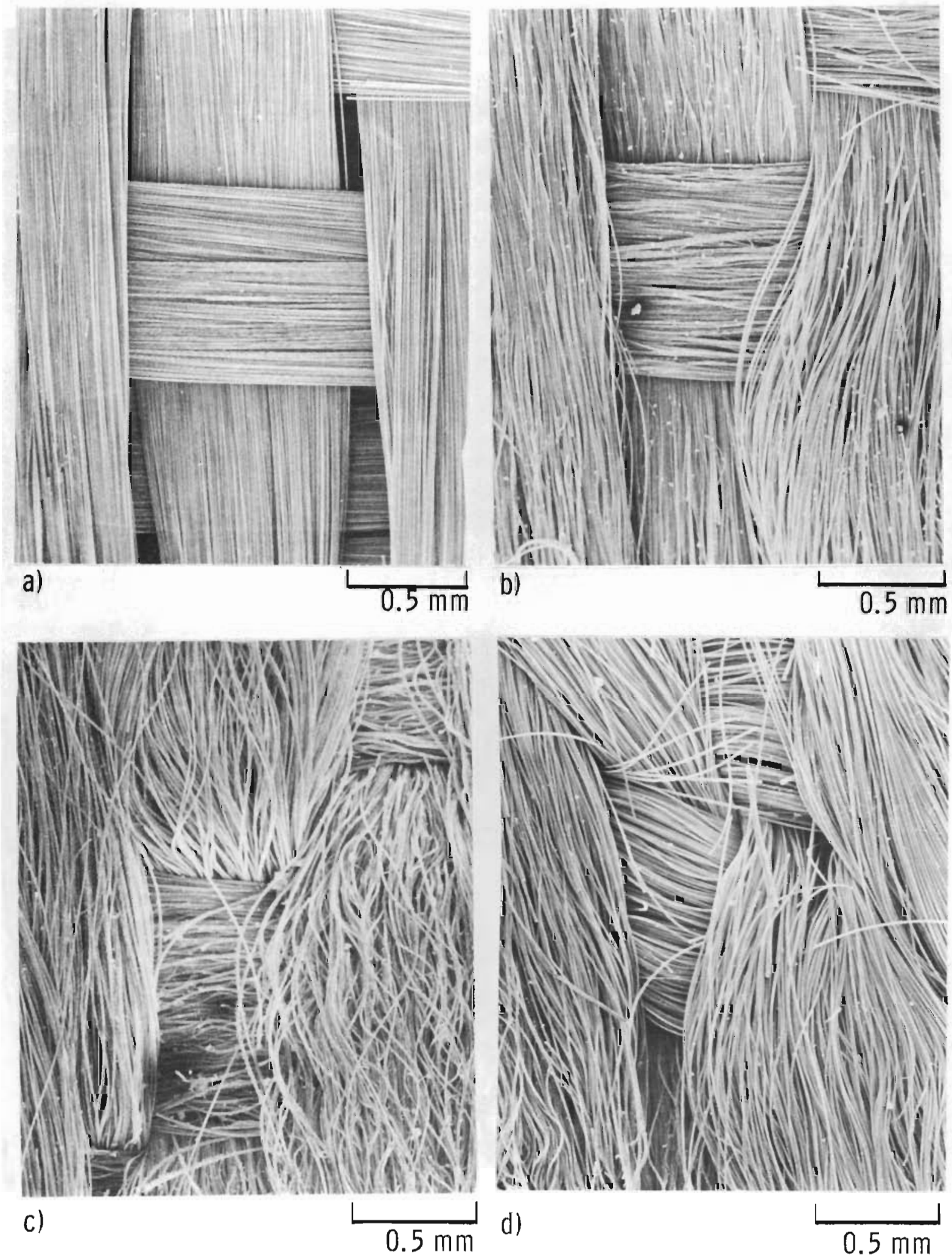

FIGURE 7. Thornel-50 Graphite C1oth; a) Unirradiated,
b) $3.5 \times 10^{21} \mathrm{~cm}-2$, c) $7.3 \times 10^{21} \mathrm{~cm}^{-2}$, d) $10 \times 10^{21} \mathrm{~cm}-2$ 


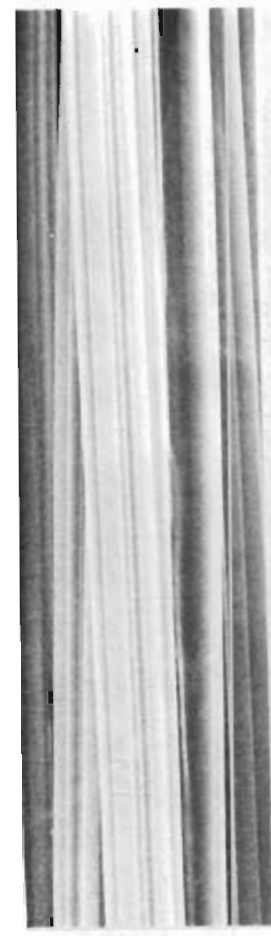

a)

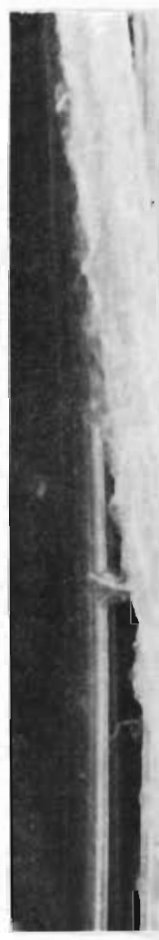

c)
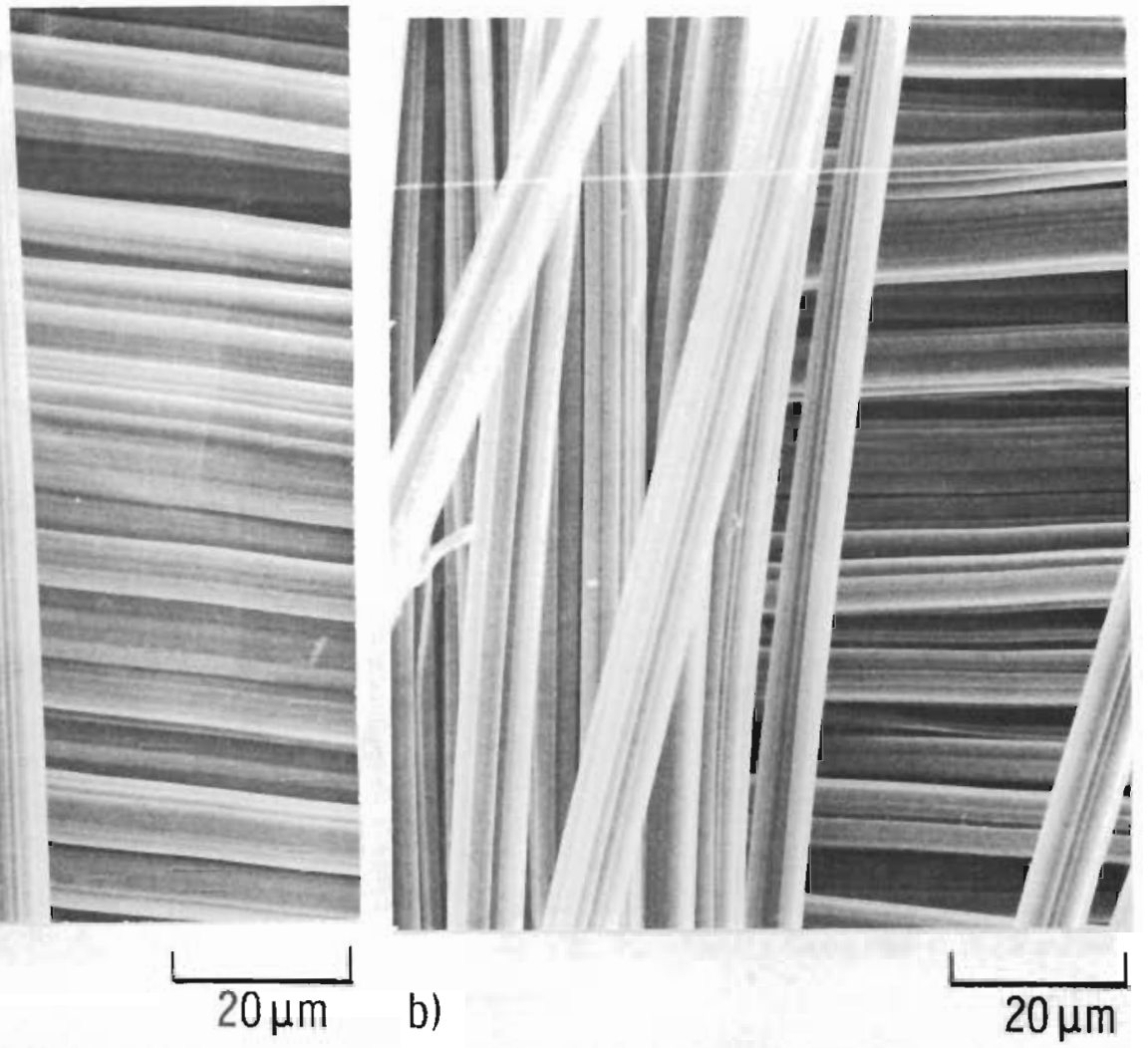

b)

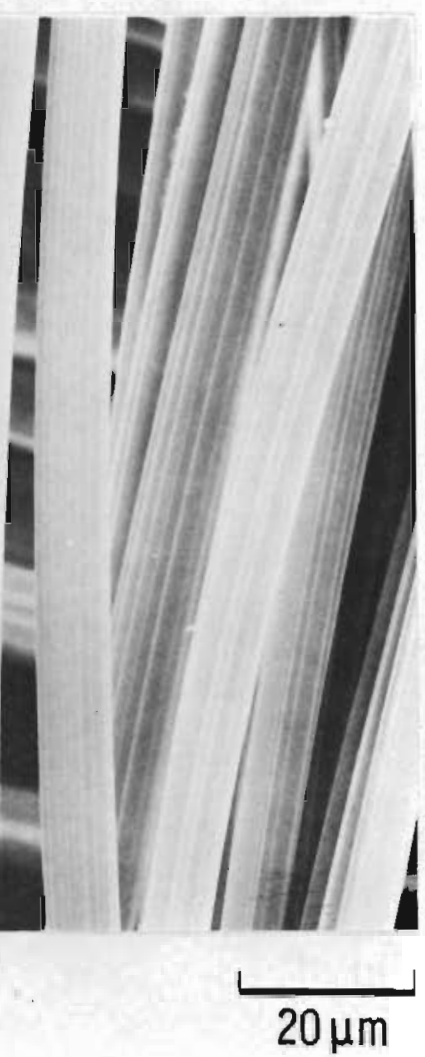

FIGURE 8. Thornel-50 Graphite Cloth; a) Unirradiated
b) $3.5 \times 10^{21} \mathrm{~cm}^{-2}$, c) $7.3 \times 10^{21} \mathrm{~cm}^{-2}$, d) $10 \times 10^{21} \mathrm{~cm}^{-2}$ 

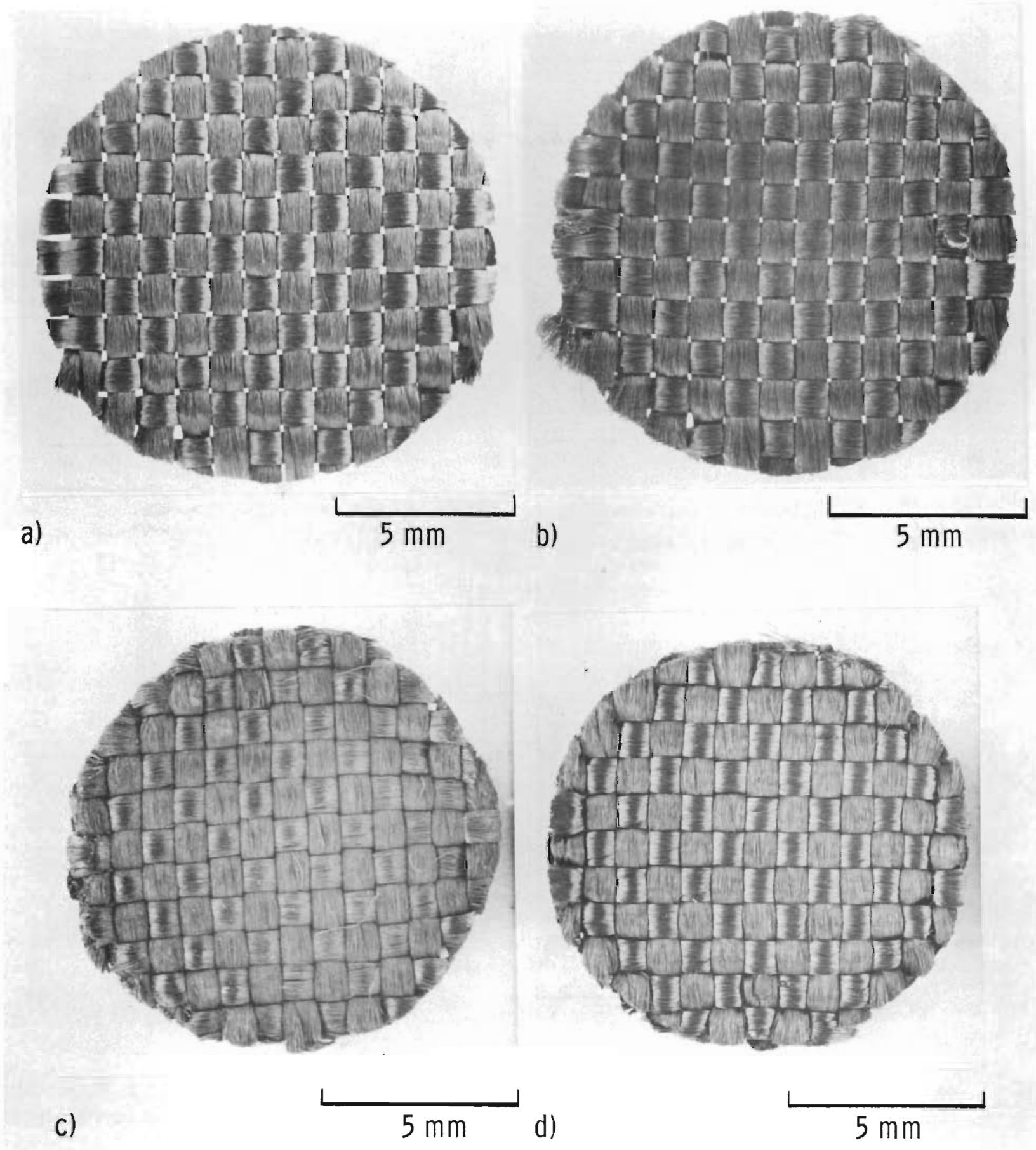

FIGURE 9. GSGC-2 Graphite Cloth; a) Unirradiated,

b) $3.5 \times 1021 \mathrm{~cm}^{-2}$, c) $7.3 \times 1021 \mathrm{~cm}^{-2}$, d) $10 \times 1021 \mathrm{~cm}^{-2}$ 

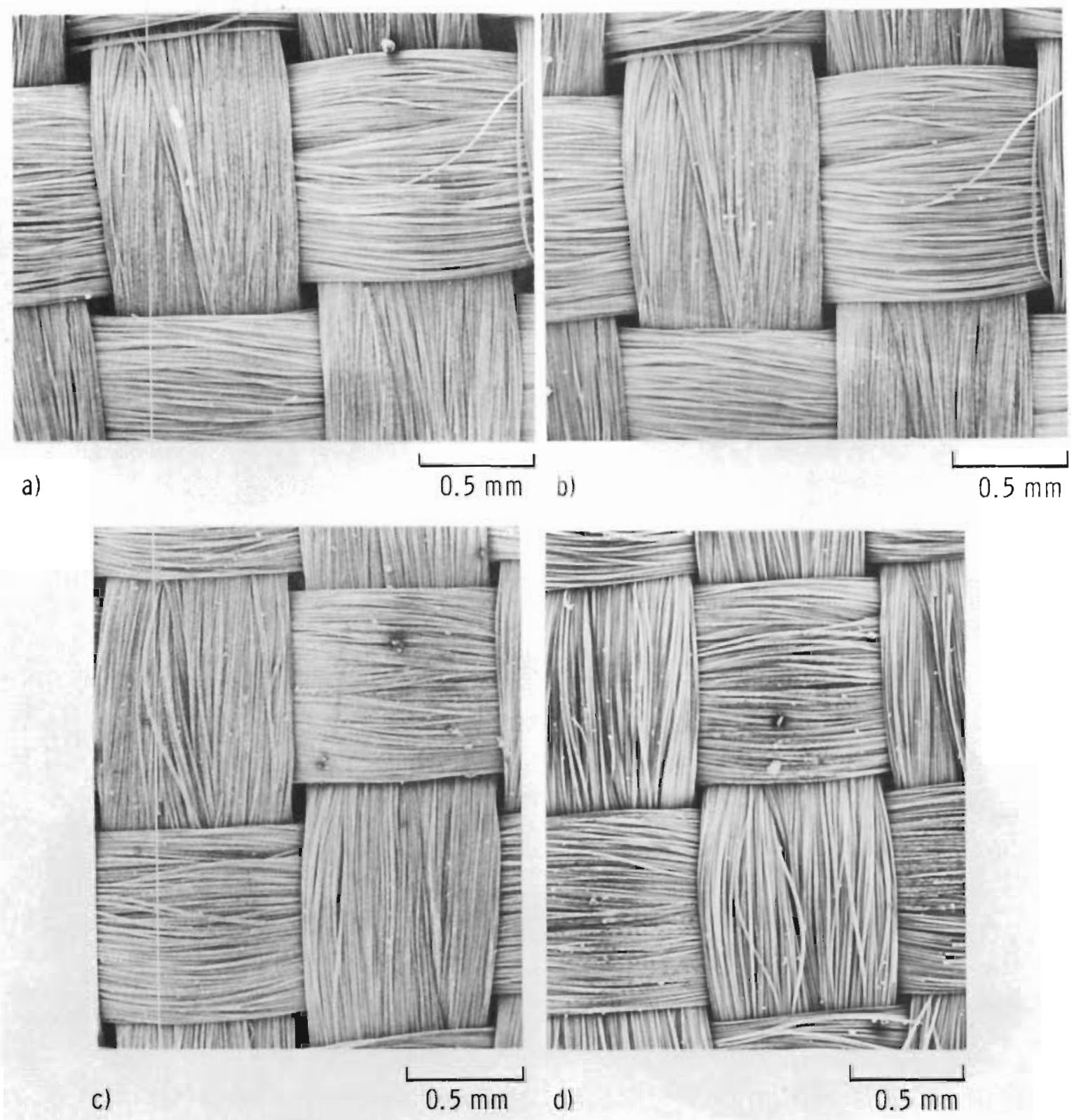

FIGURE 10. GSGC-2 Graphite C1oth; a) Unirradiated, b) $3.5 \times 10^{21} \mathrm{~cm}^{-2}$, c) $7.3 \times 10^{21} \mathrm{~cm}^{-2}$, d) $10 \times 10^{21} \mathrm{~cm}^{-2}$ 


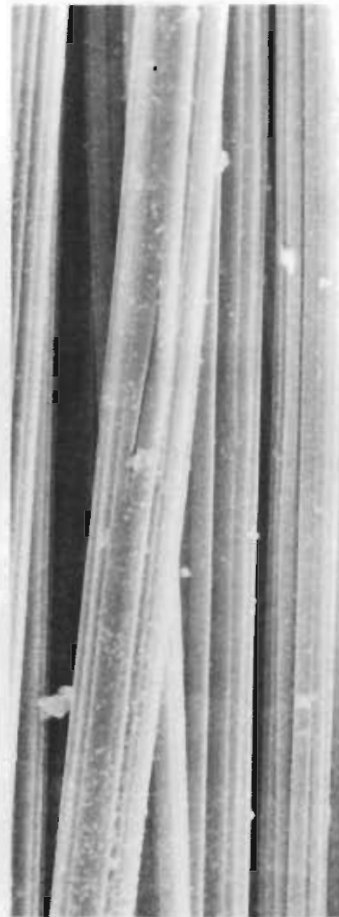

a)

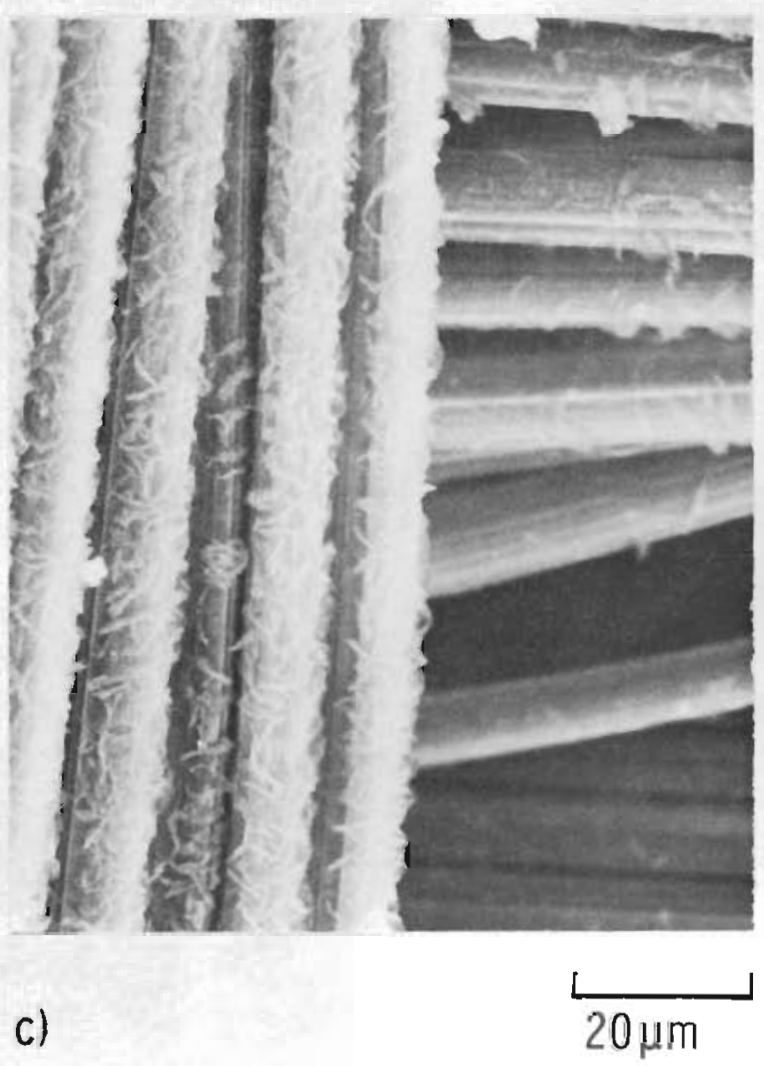

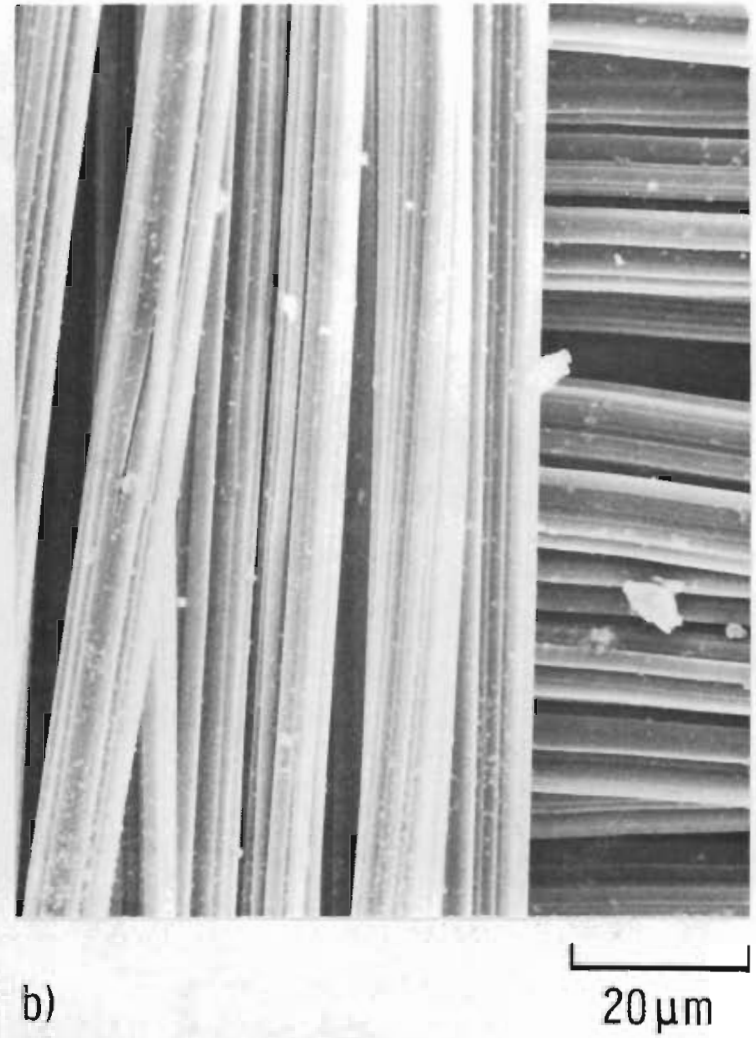

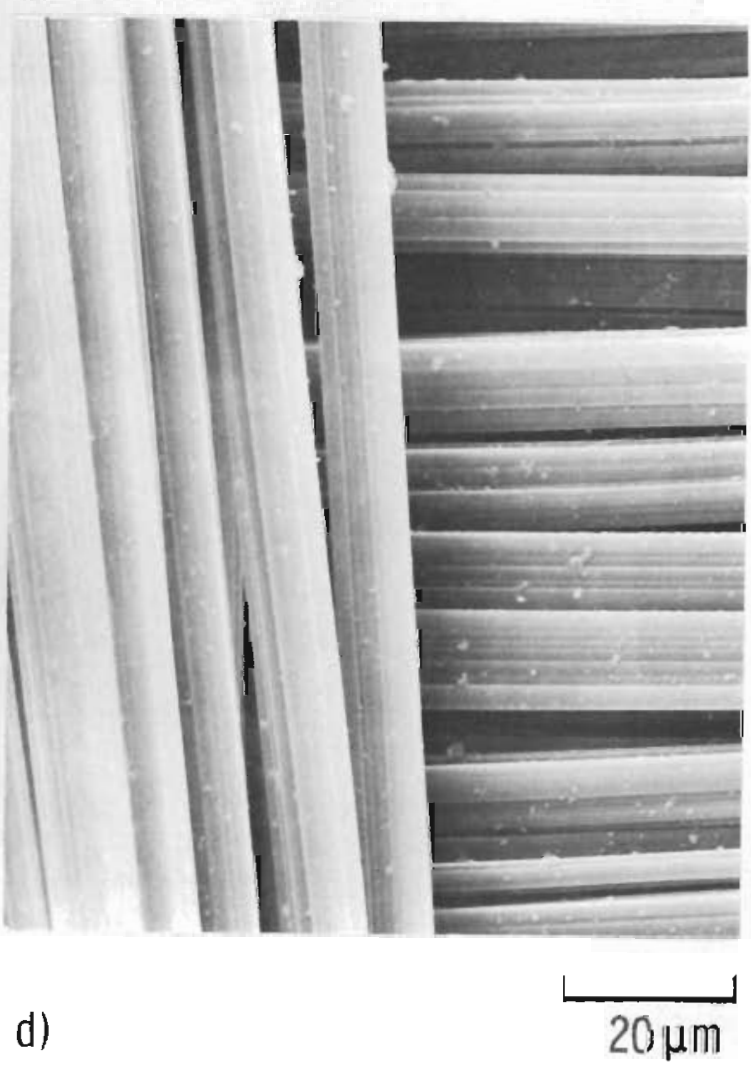

FIGURE 11. GSGC-2 Graphite C1oth; a) Unirradiated, b) $3.5 \times 10^{21} \mathrm{~cm}^{-2}$, c) $7.3 \times 10^{21} \mathrm{~cm}^{-2}$, d) $10 \times 10^{21} \mathrm{~cm}^{-2}$ 


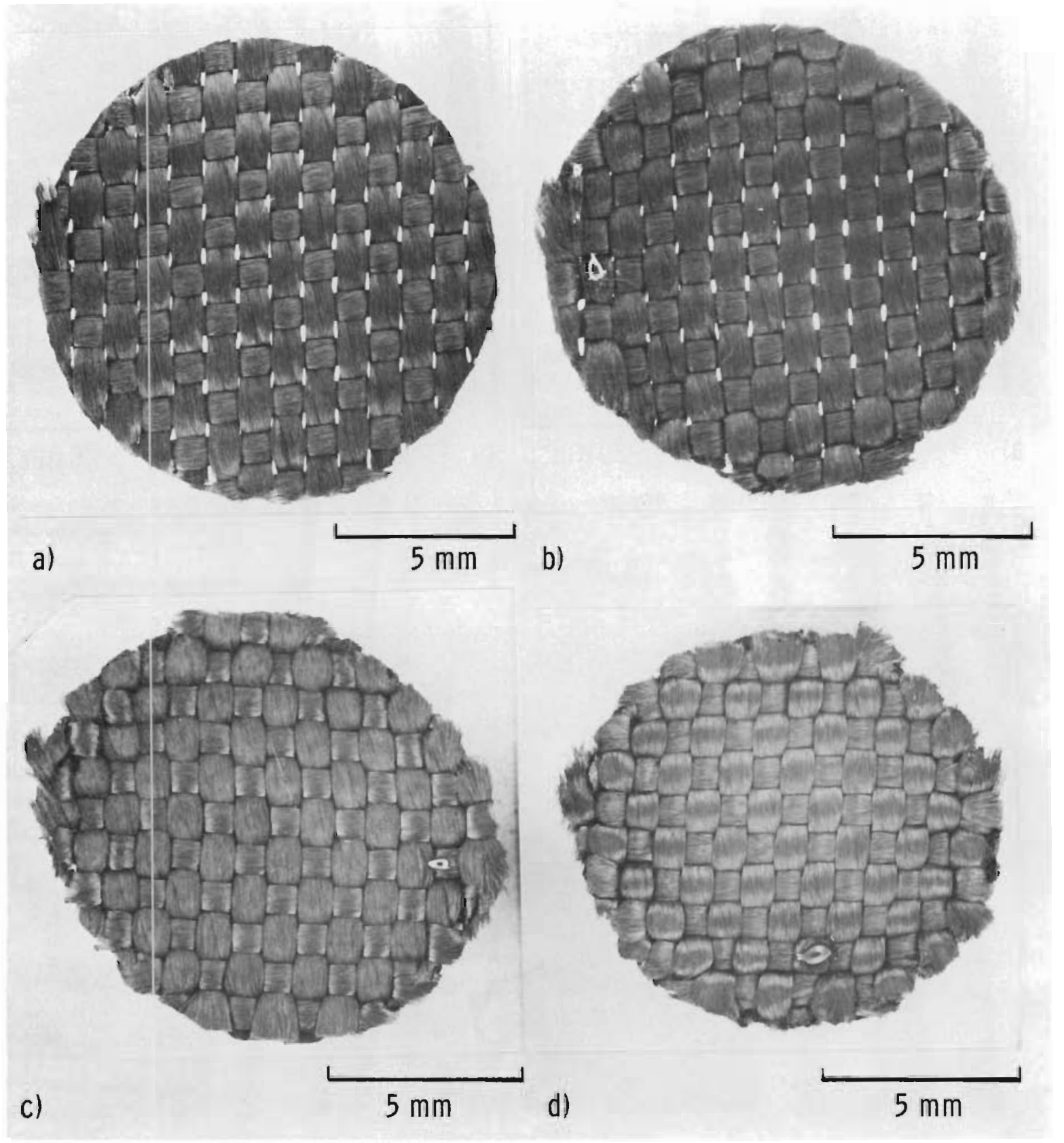

FIGURE 12. WCA Graphite C1oth; a) Unirradiated,

b) $\left.3.5 \times 10^{21} \mathrm{~cm}^{-2}, \mathrm{c}\right) 7.3 \times 10^{21} \mathrm{~cm}^{-2}$, d) $10 \times 10^{21} \mathrm{~cm}^{-2}$ 

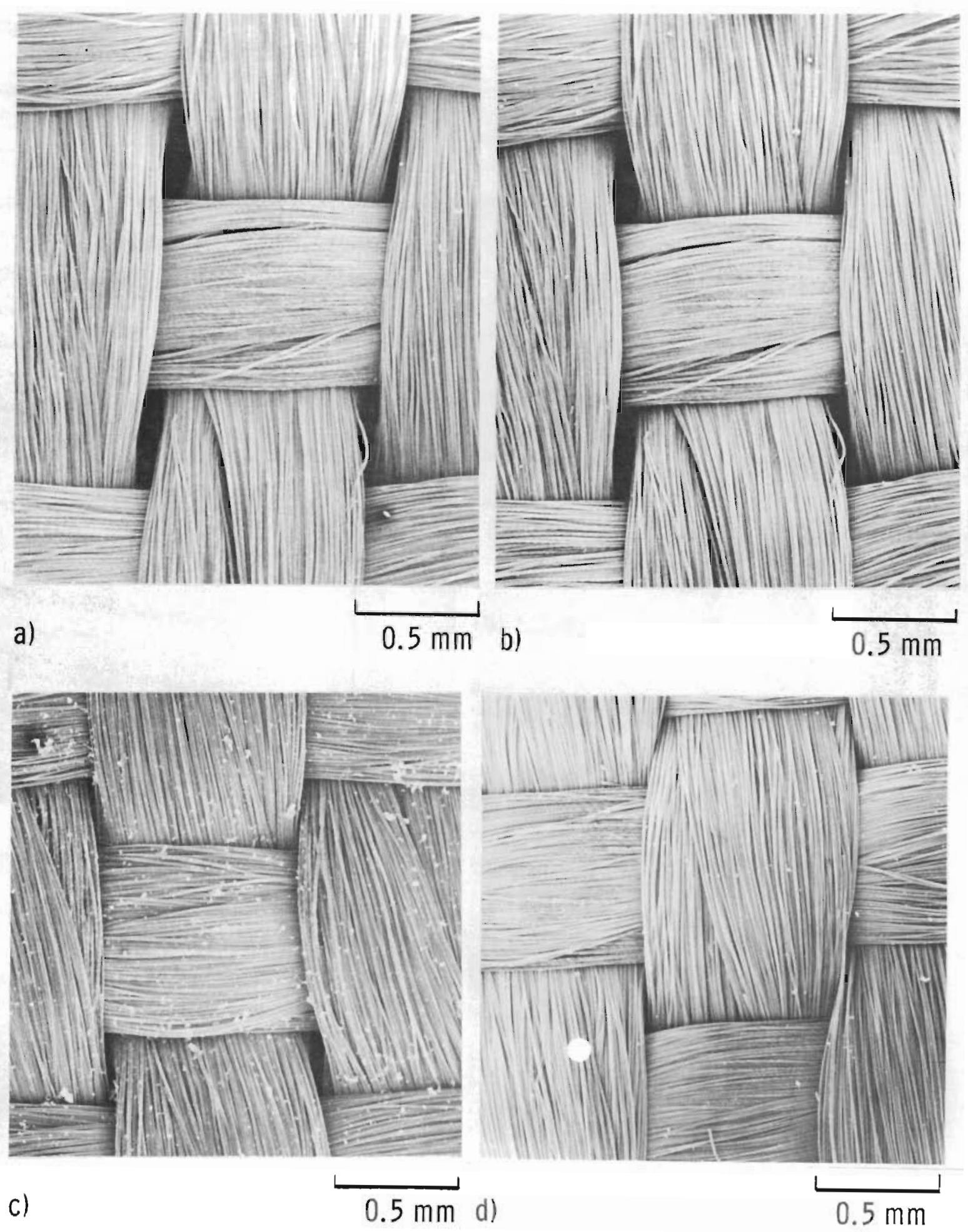

FIGURE 13. WLA Graphlte Cloth; a) Unirradiated,

b) $3.5 \times 10^{21} \mathrm{~cm}^{-2}$, c) $7.3 \times 10^{21} \mathrm{~cm}-2$, d) $10 \times 10^{21} \mathrm{~cm}-2$ 

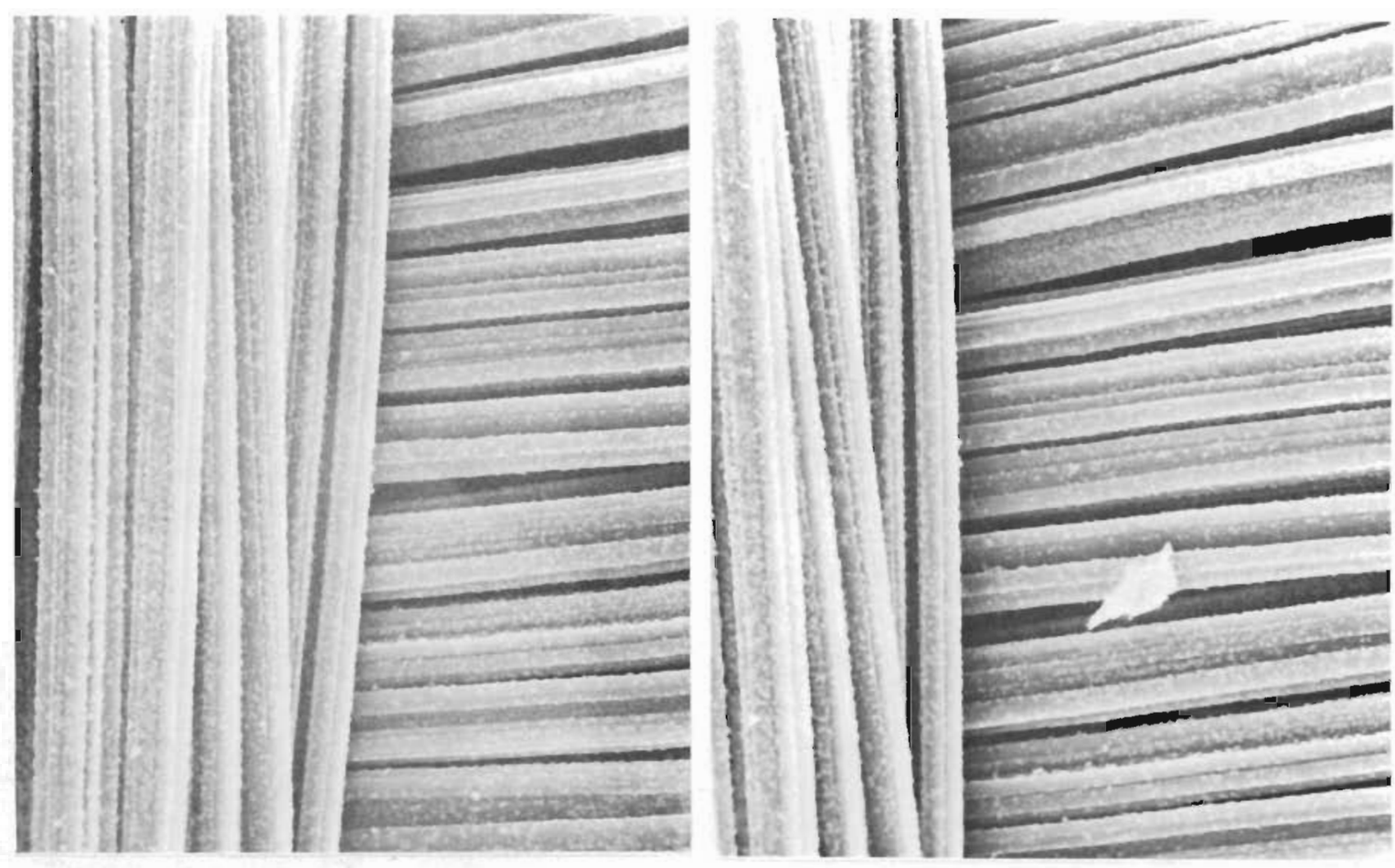

a)
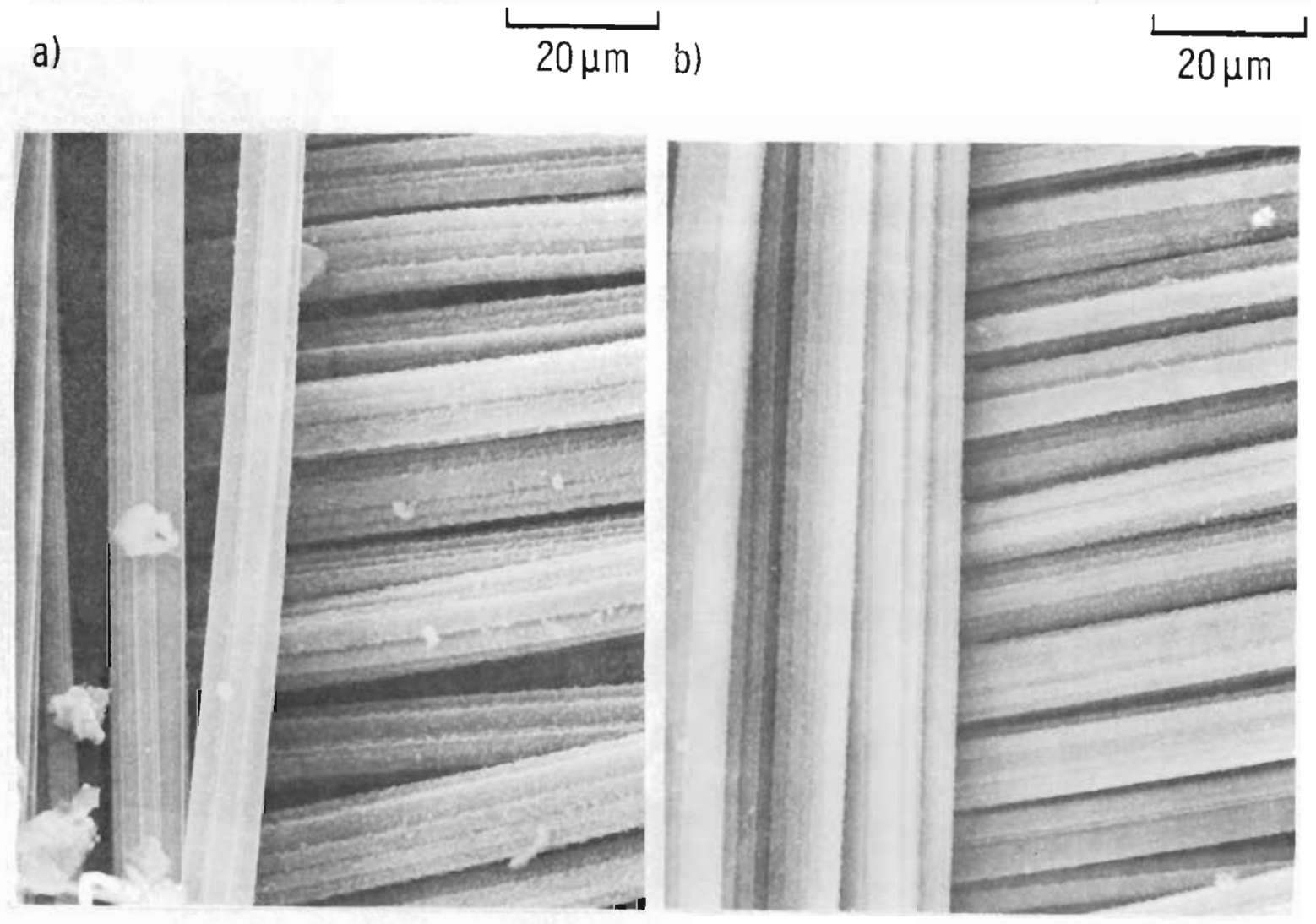

c)
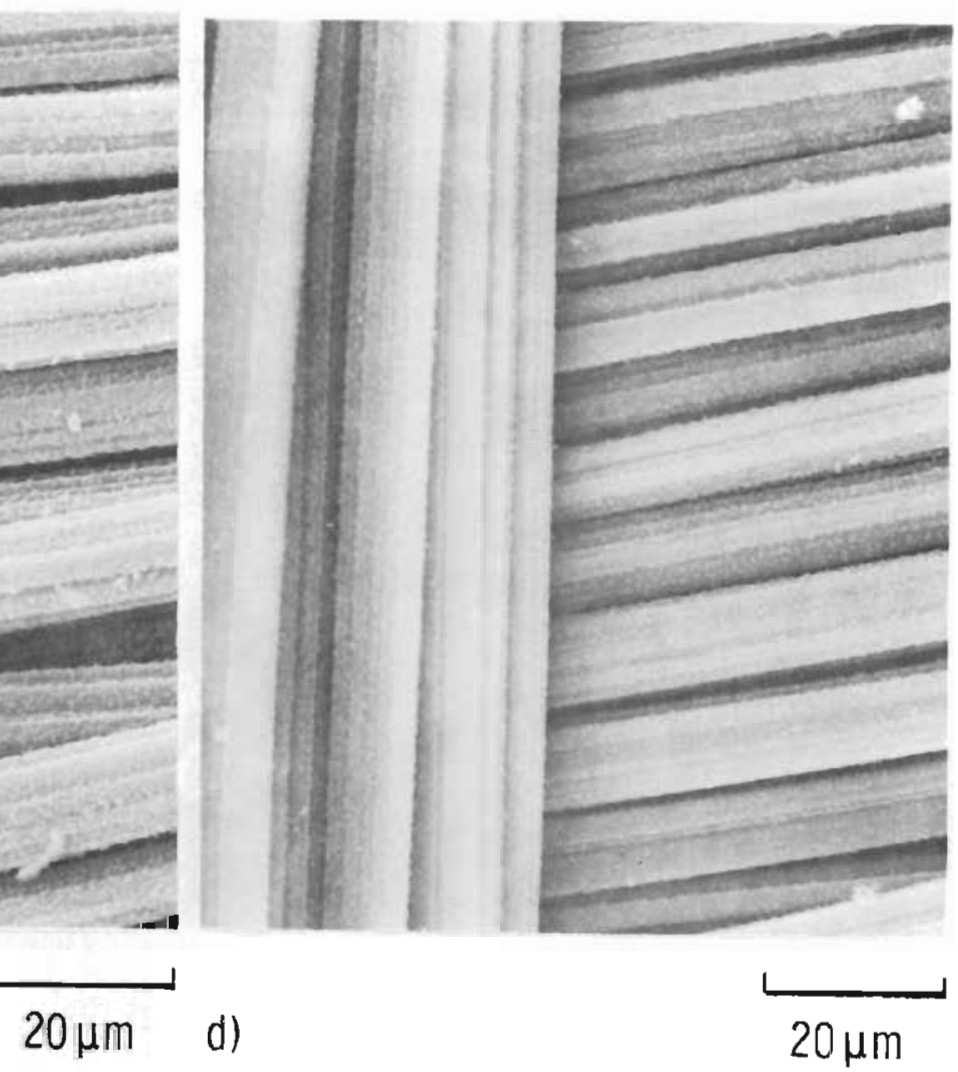

FIGURE 14. WCA Graphite Cloth; a) Unirradiated, b) $\left.\left.3.5 \times 10^{21} \mathrm{~cm}^{-2}, \mathrm{c}\right) 7.3 \times 10^{21} \mathrm{~cm}^{-2}, \mathrm{~d}\right) 10 \times 10^{21} \mathrm{~cm}-2$ 

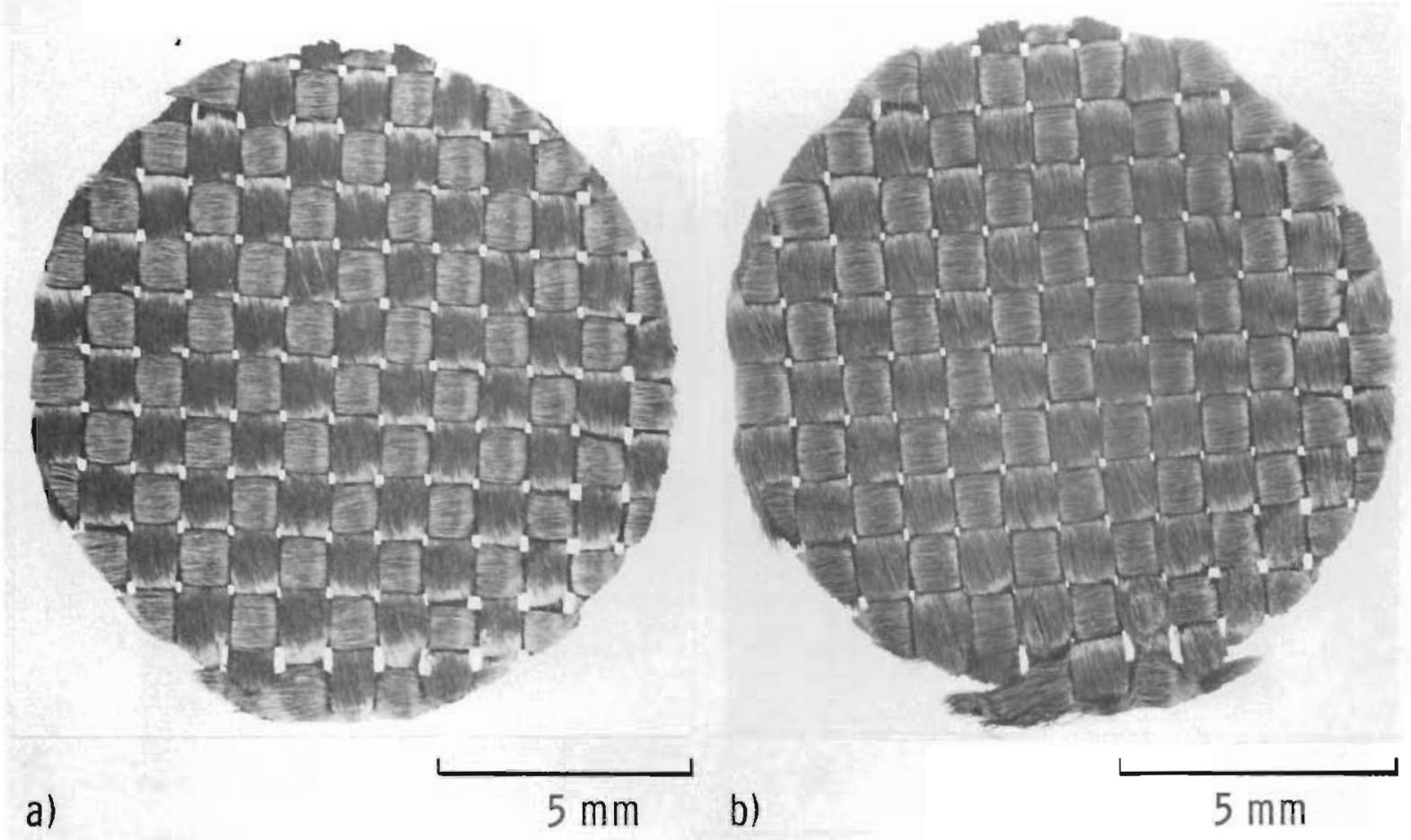

a)

$5 \mathrm{~mm} \quad$ b)

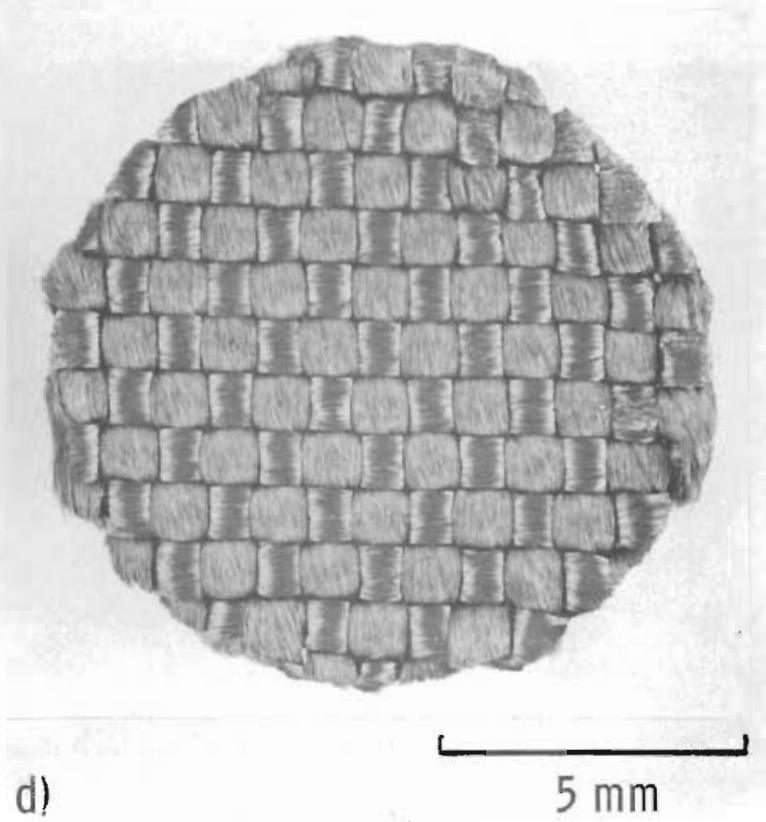

c)

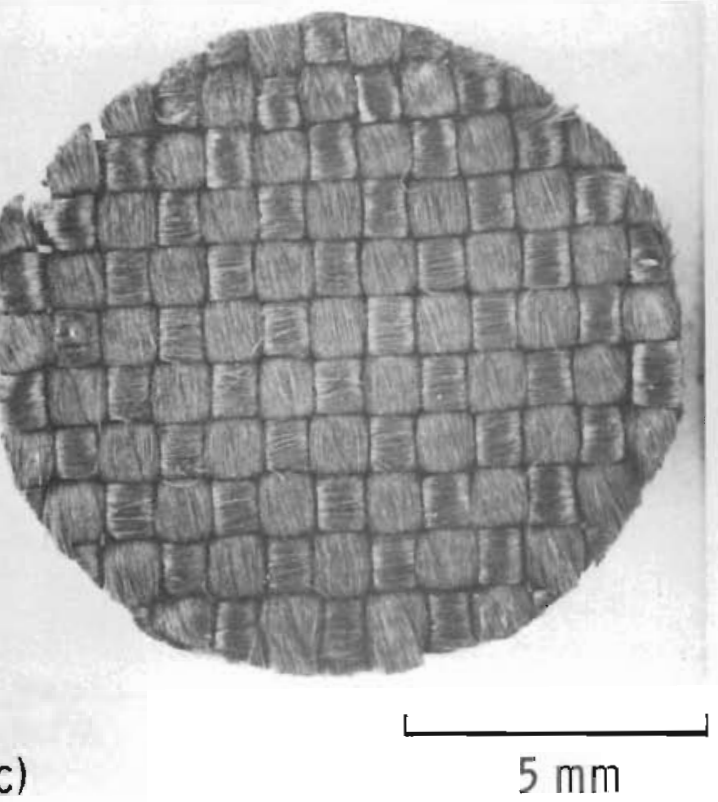

FIGURE 15. GSCC-2 Carbon Cloth; a) Unirradiated, b) $3.5 \times 10^{21} \mathrm{~cm}^{-2}$, c) $7.3 \times 10^{21} \mathrm{~cm}^{-2}$, d) $10 \times 10^{21} \mathrm{~cm}^{-2}$ 

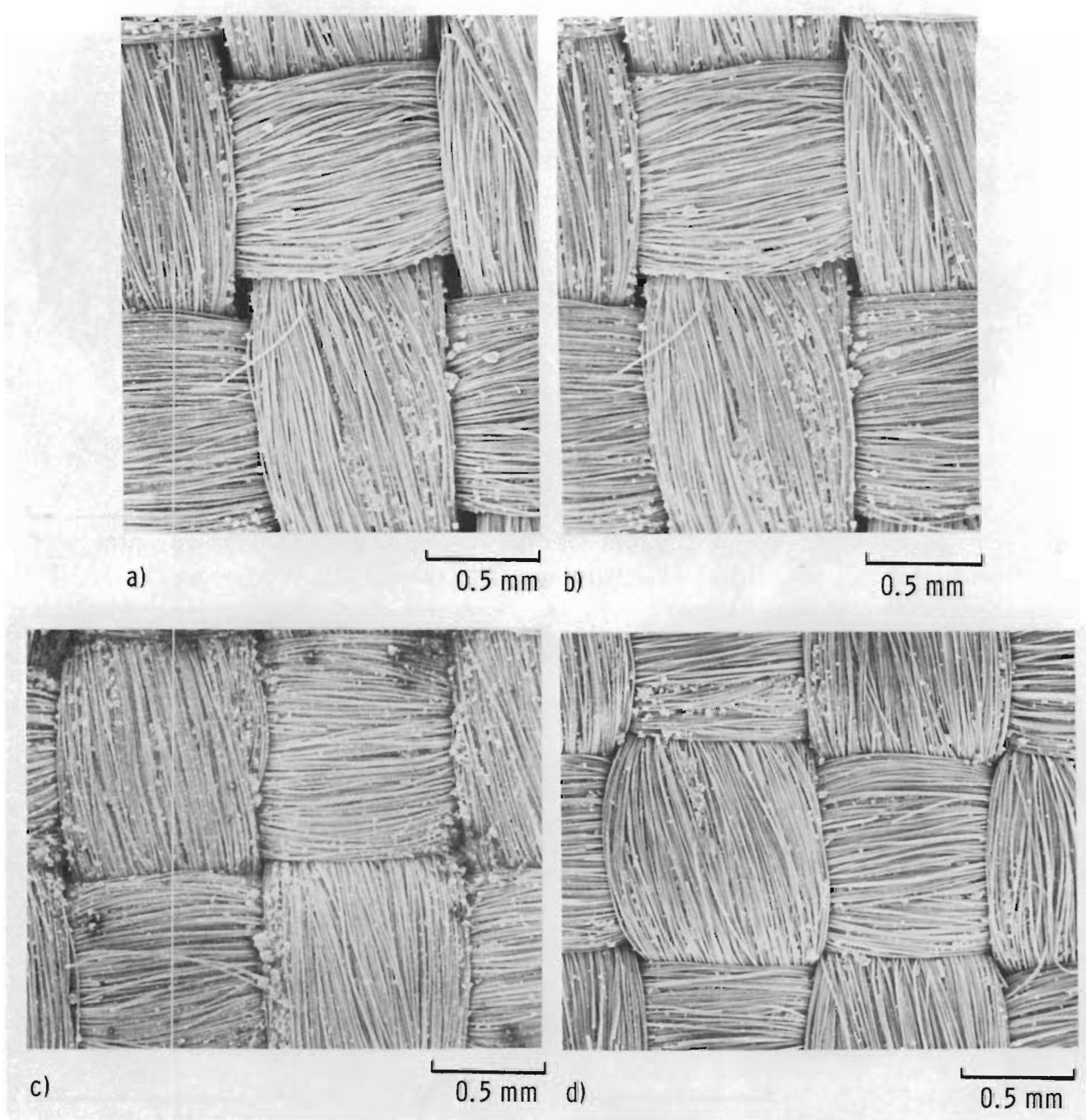

FIGURE 6. GSCC-2 Carbon Cloth; a) Unirradiated, b) $3.5 \times 10^{21} \mathrm{~cm}^{-2}$, c) $7.3 \times 10^{21} \mathrm{~cm}-2$, d) $10 \times 10^{21} \mathrm{~cm}-2$ 


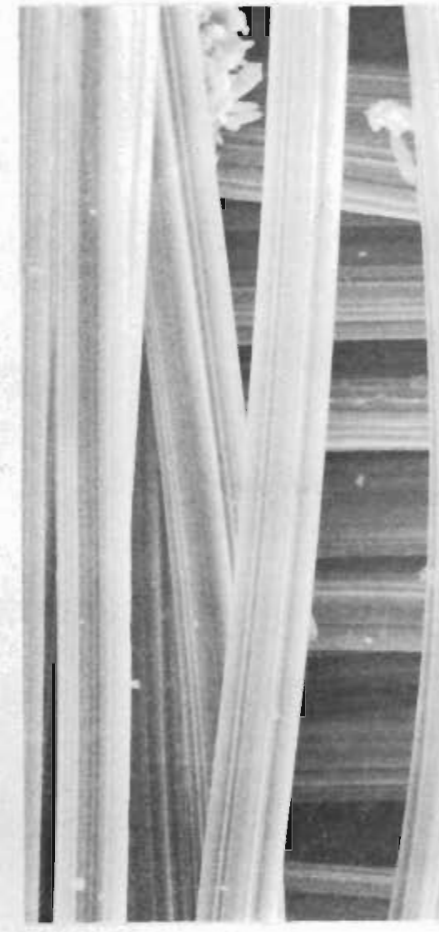

a)

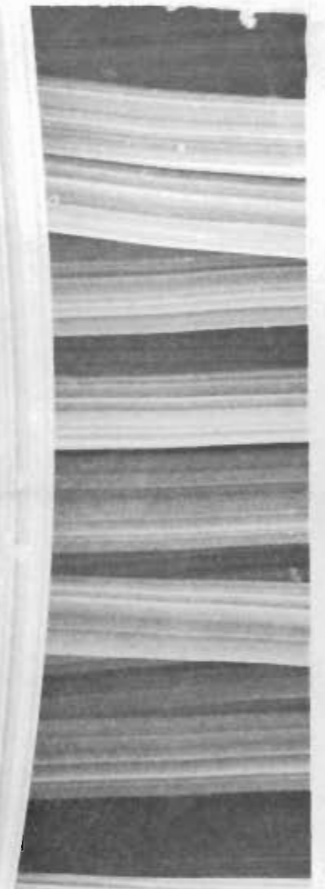

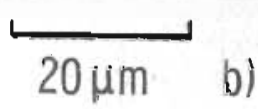

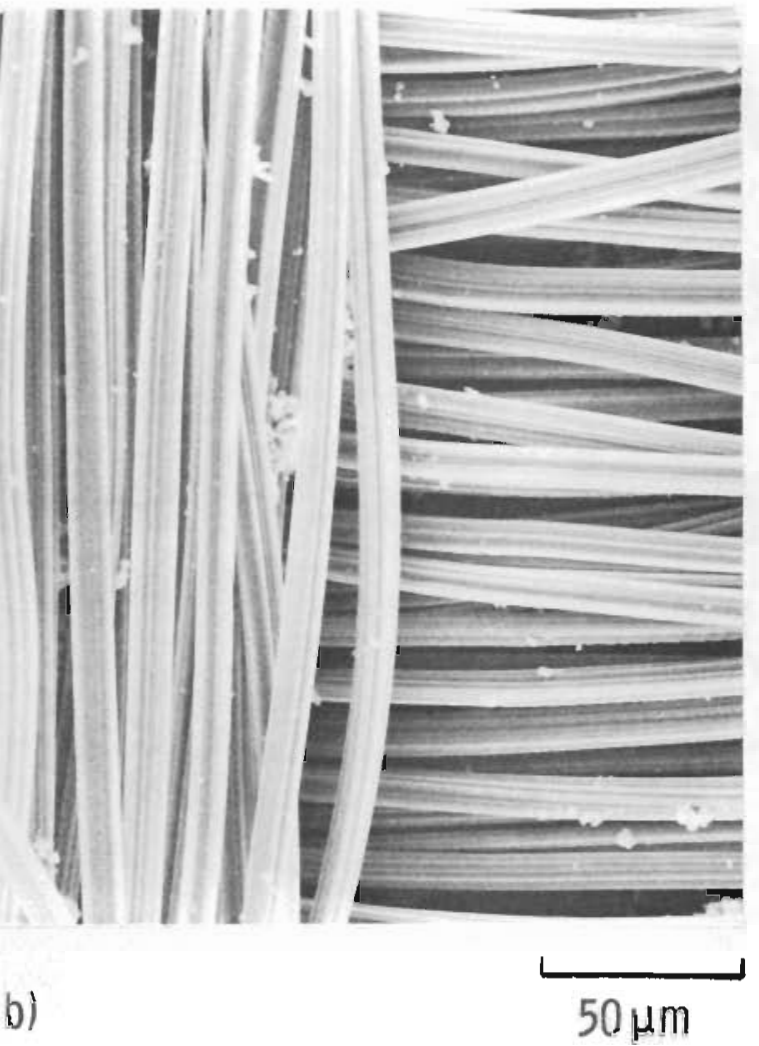

$50 \mu \mathrm{m}$

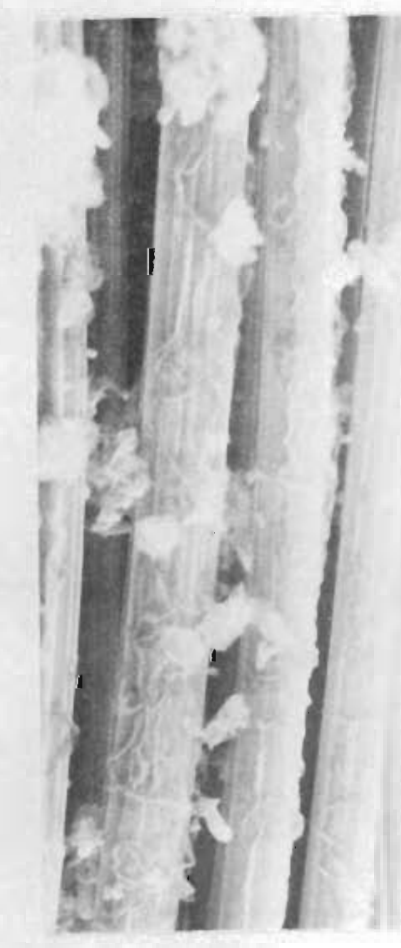

c)
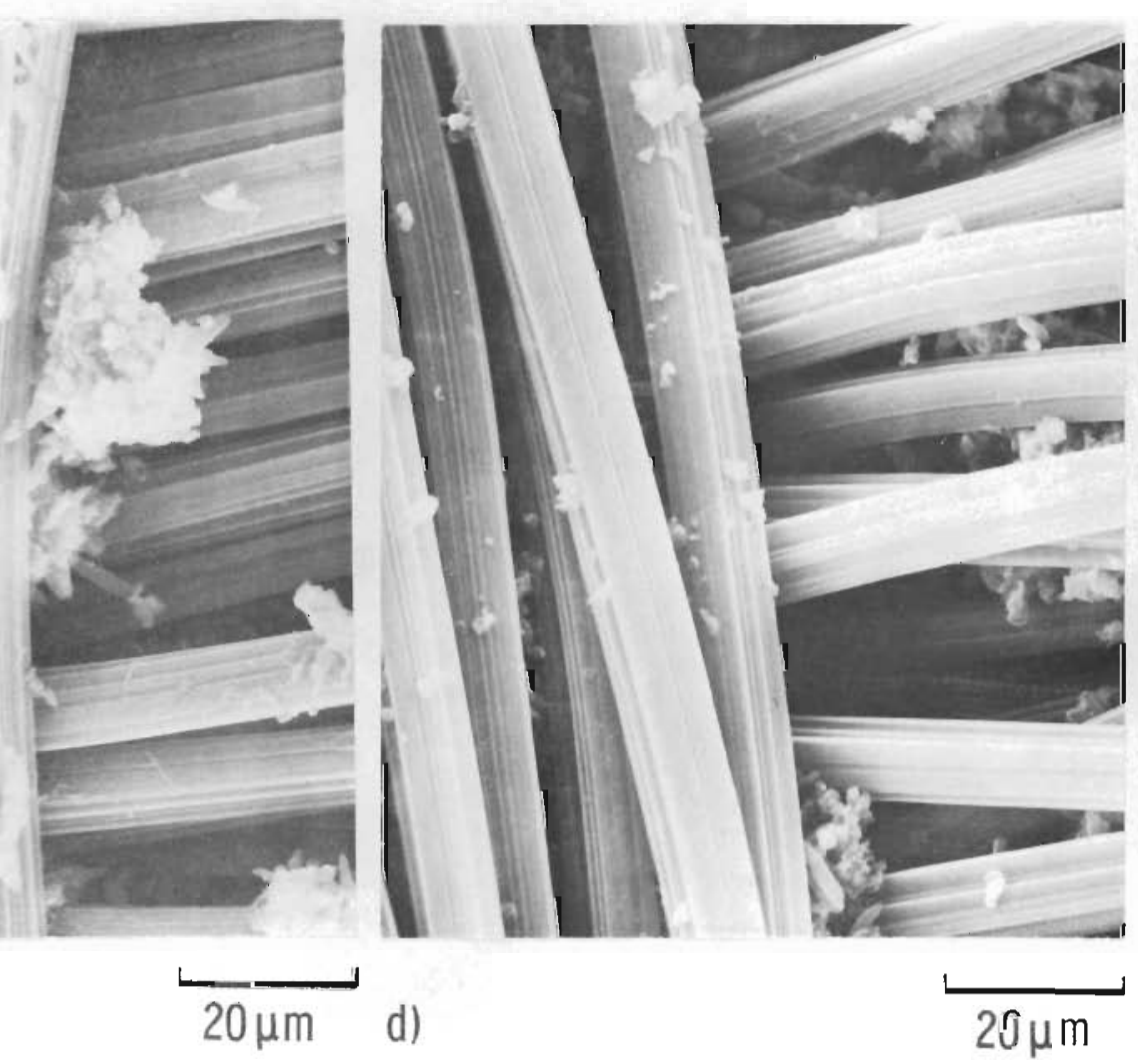

FIGURE 17. GSCC-2 Carbon Cloth; a) Unirradiated, b) $3.5 \times 10^{21} \mathrm{~cm}^{-2}$, c) $7.3 \times 1021 \mathrm{~cm}^{-2}$, d) $10 \times 1021 \mathrm{~cm}^{-2}$ 


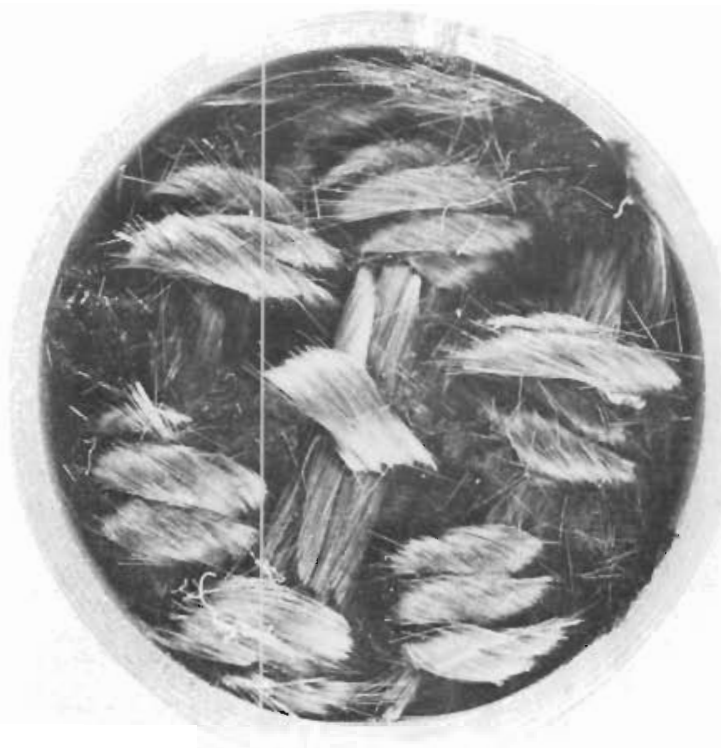

a)

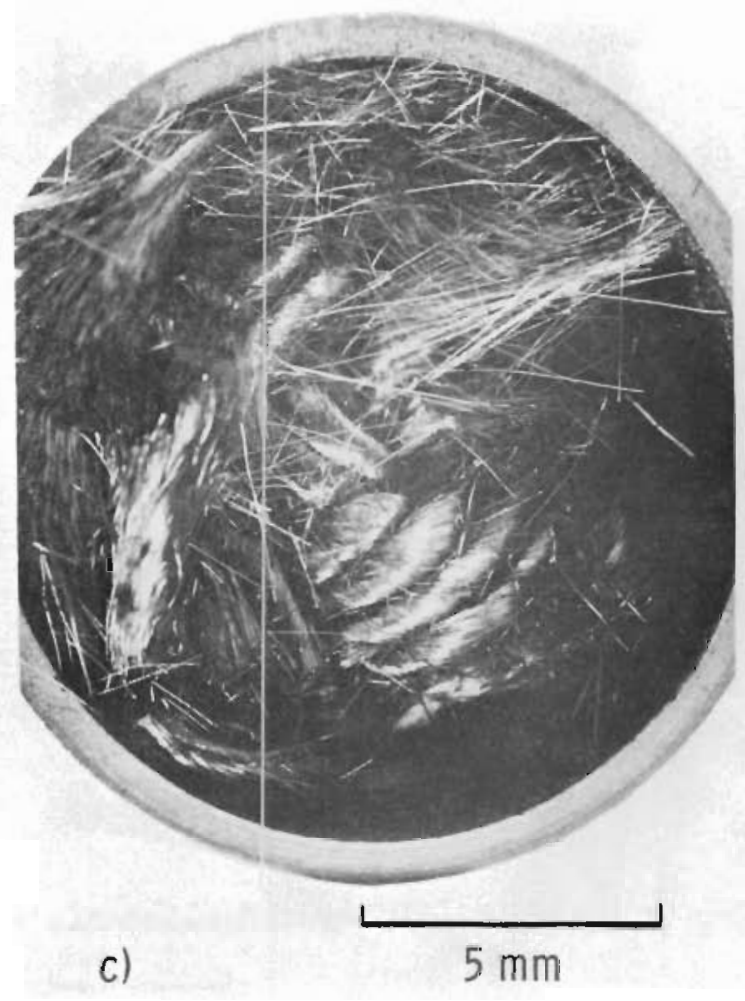

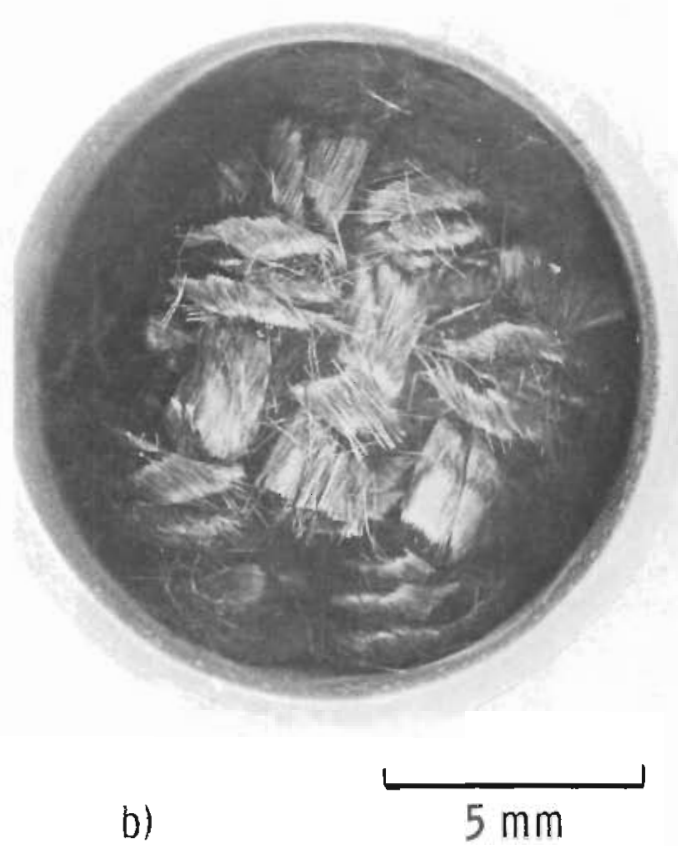

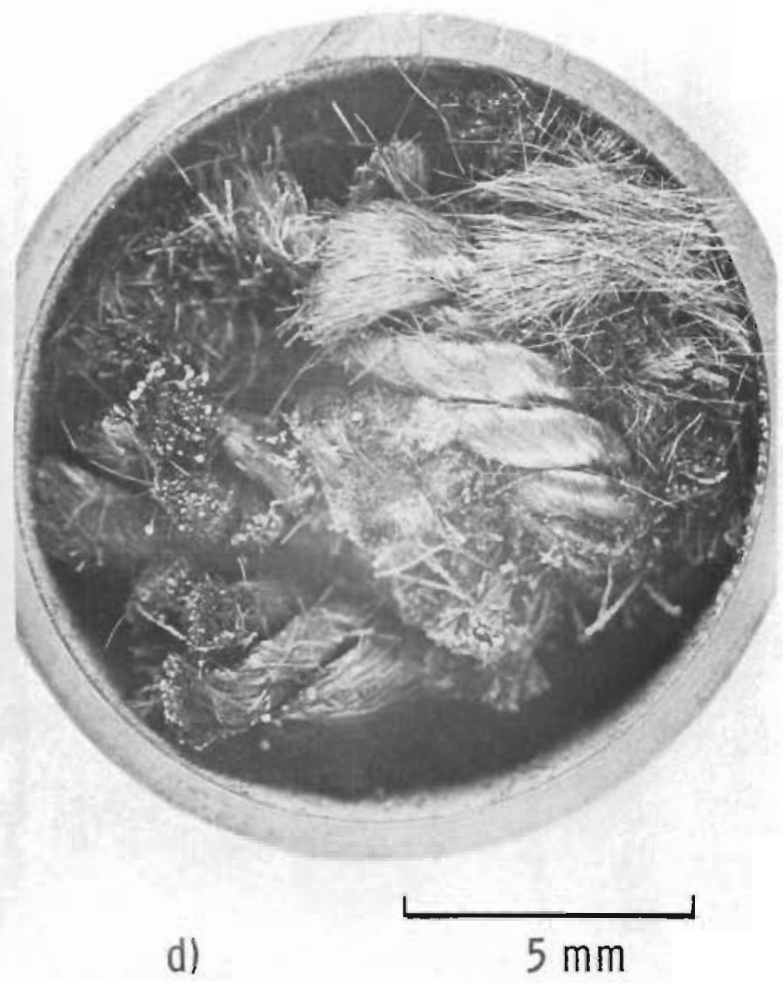

FIGURE 18. Thornel-400 Carbon Cloth, 3-D Orthogonal Weave; a) Unirradiated, b) $4.1 \times 10^{21} \mathrm{~cm}^{-2}$, c) $8.5 \times 10^{21} \mathrm{~cm}^{-2}$, d) $11.7 \times 10^{21} \mathrm{~cm}-2$ 


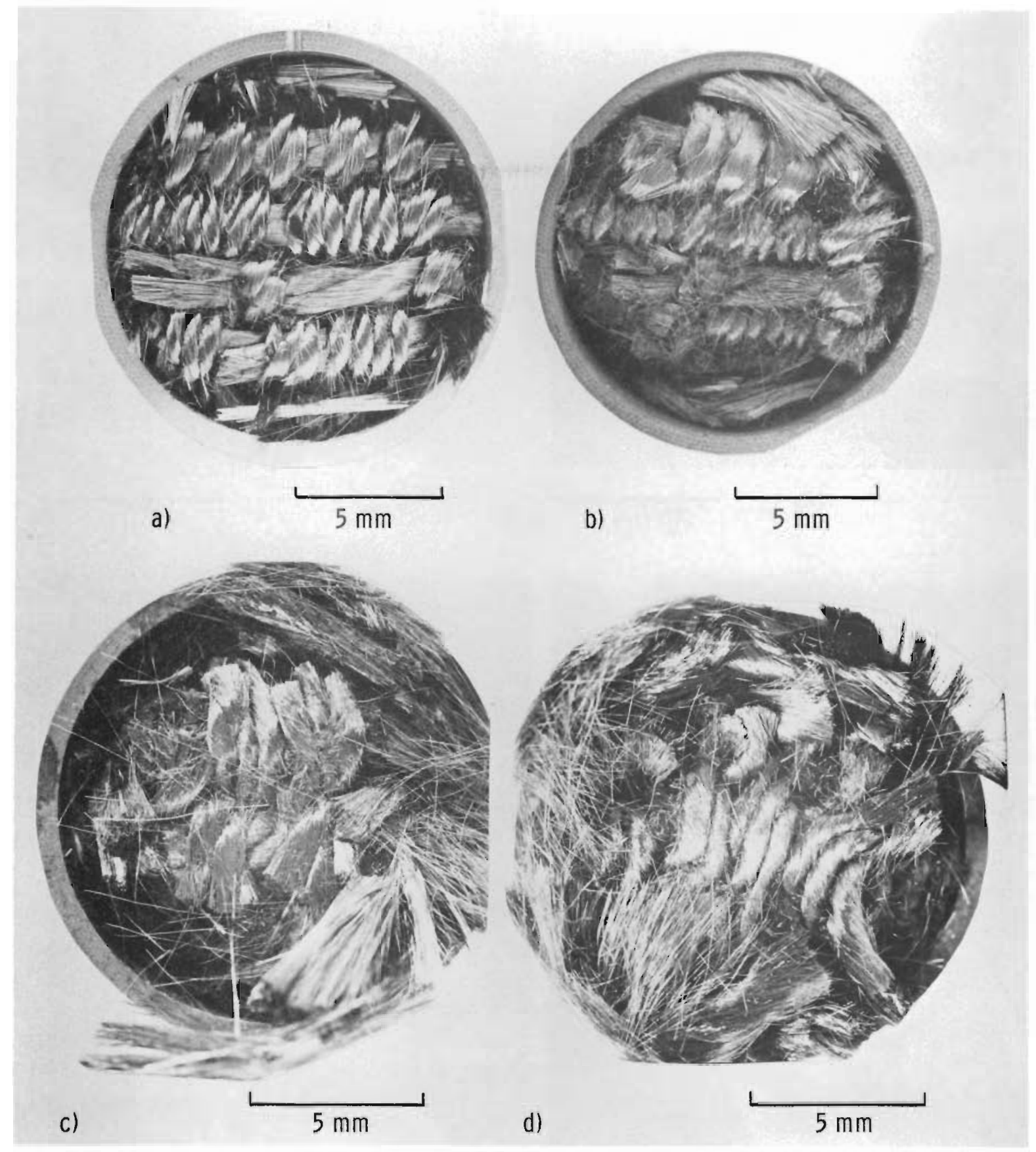

FIGURE 19. Thorne1-400 Carbon Cloth, 3-D Angle Interlock Weave; a) Unirradiated, b) $4.1 \times 10^{21} \mathrm{~cm}^{-2}$, c) $8.5 \times 10^{21} \mathrm{~cm}^{-2}$, d) $11.7 \times 10^{21} \mathrm{~cm}^{-2}$ 


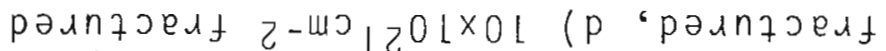

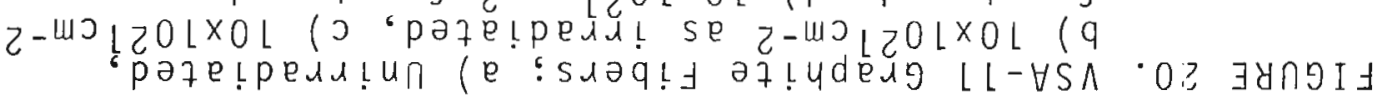
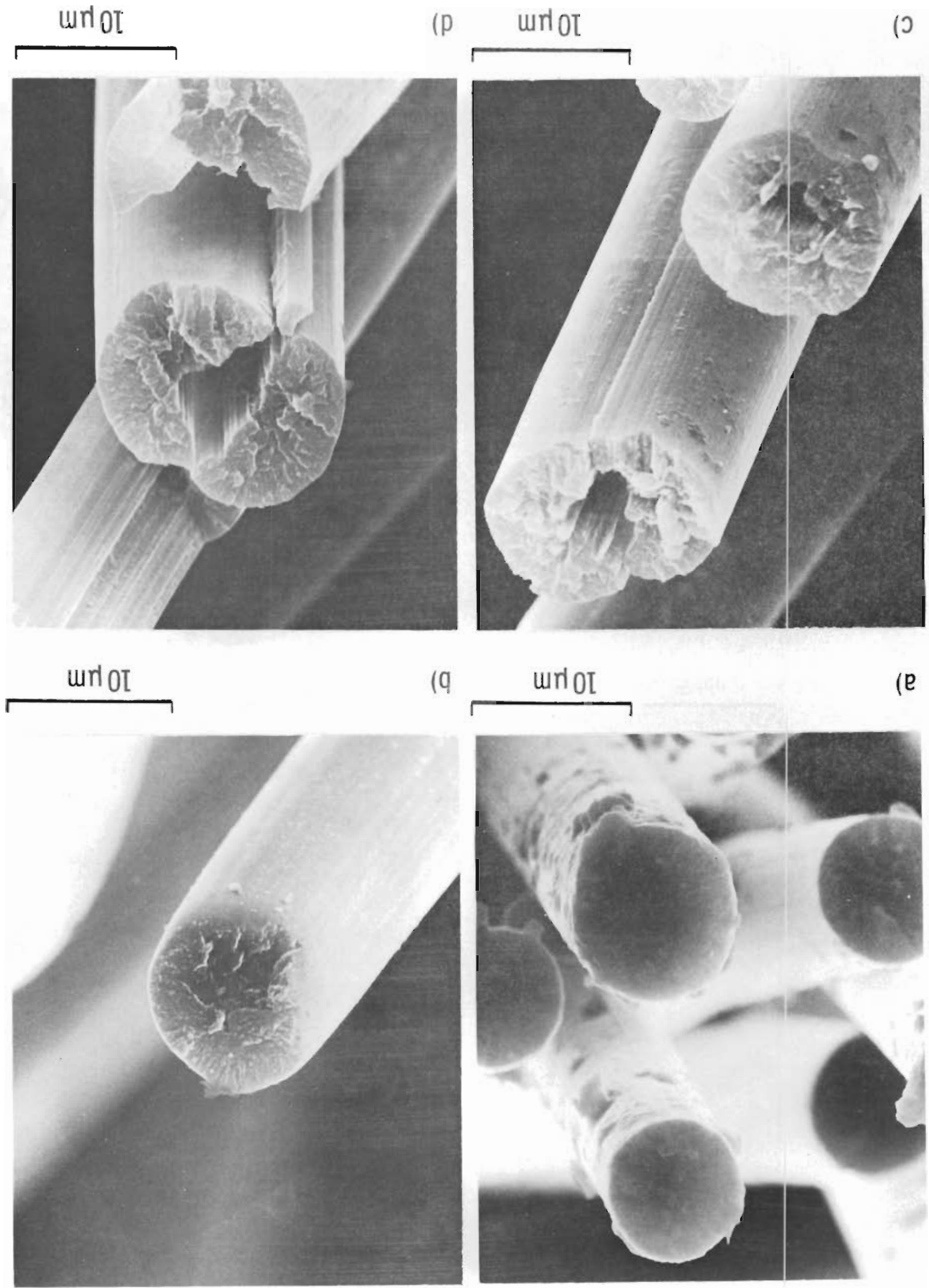

(e

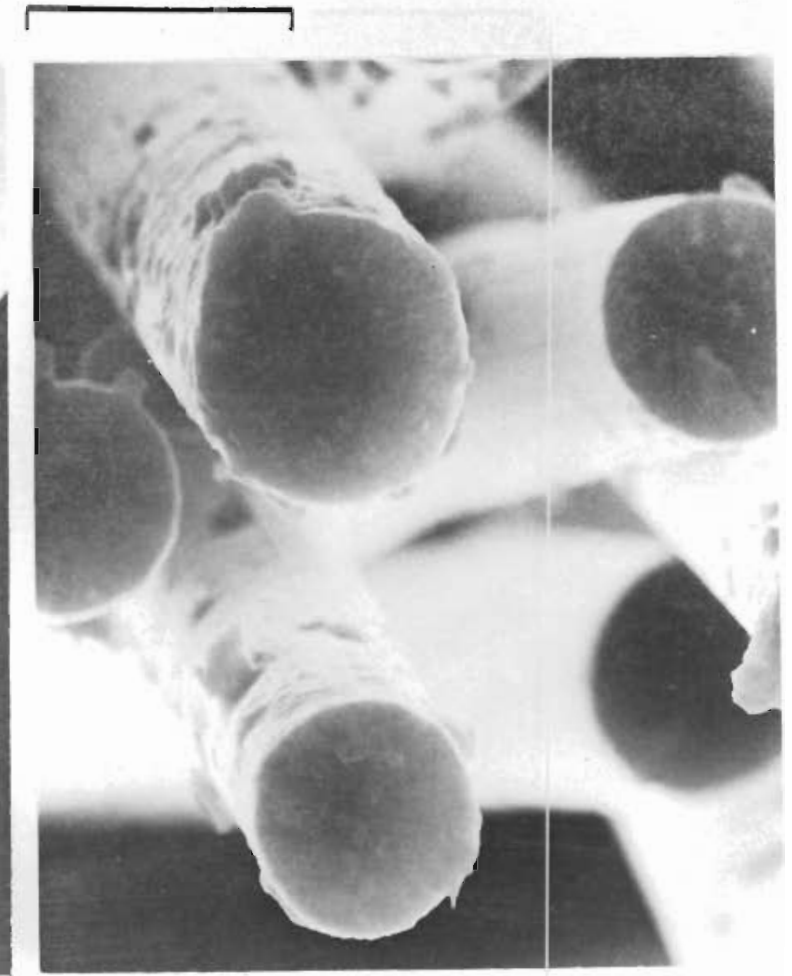



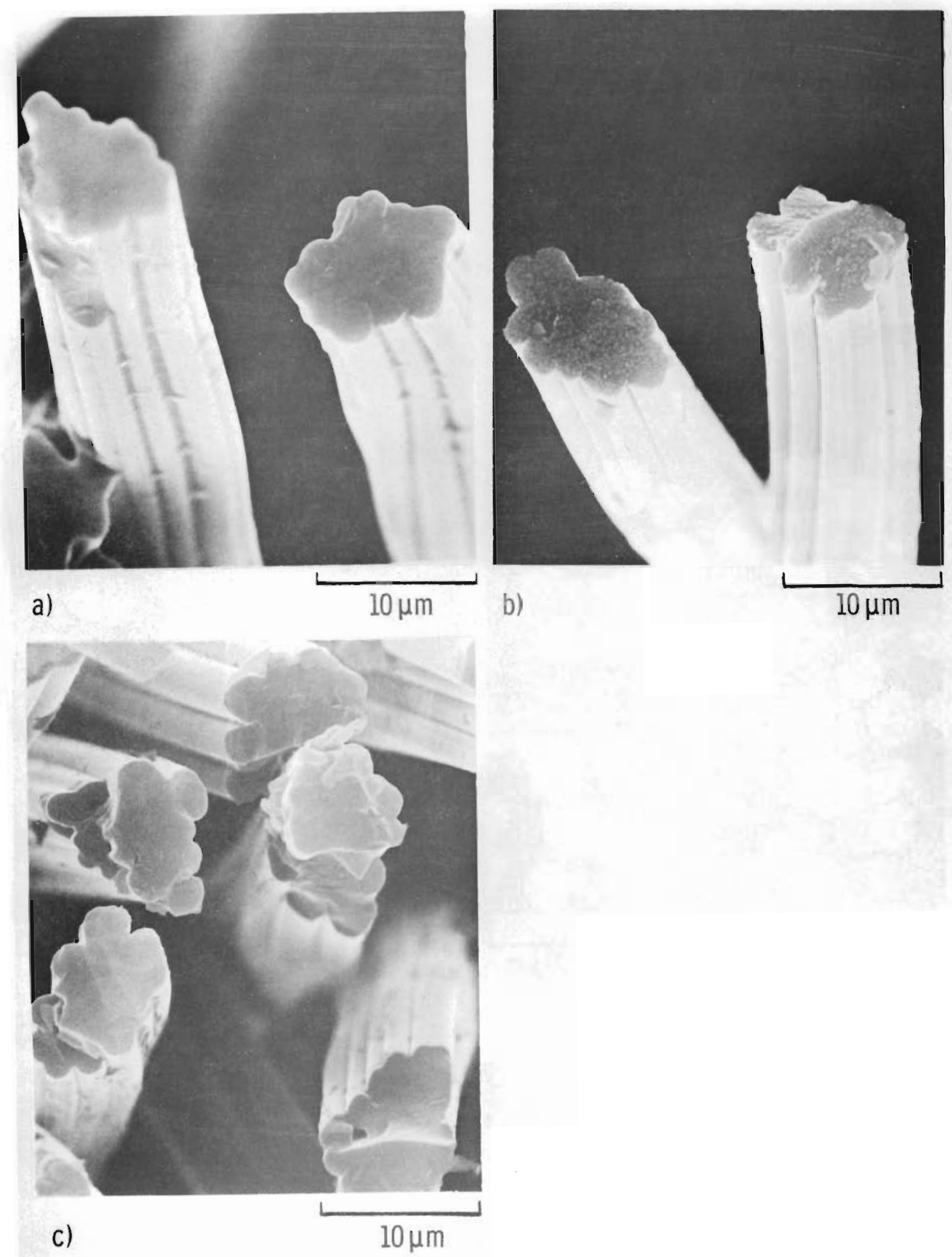

FIGURE 21. C-20 Carbon Fibers; a) Unirradiated,

b) $10 \times 10^{21} \mathrm{~cm}^{-2}$ as irradiated c) $10 \times 10^{21} \mathrm{~cm}^{-2}$ fractured 

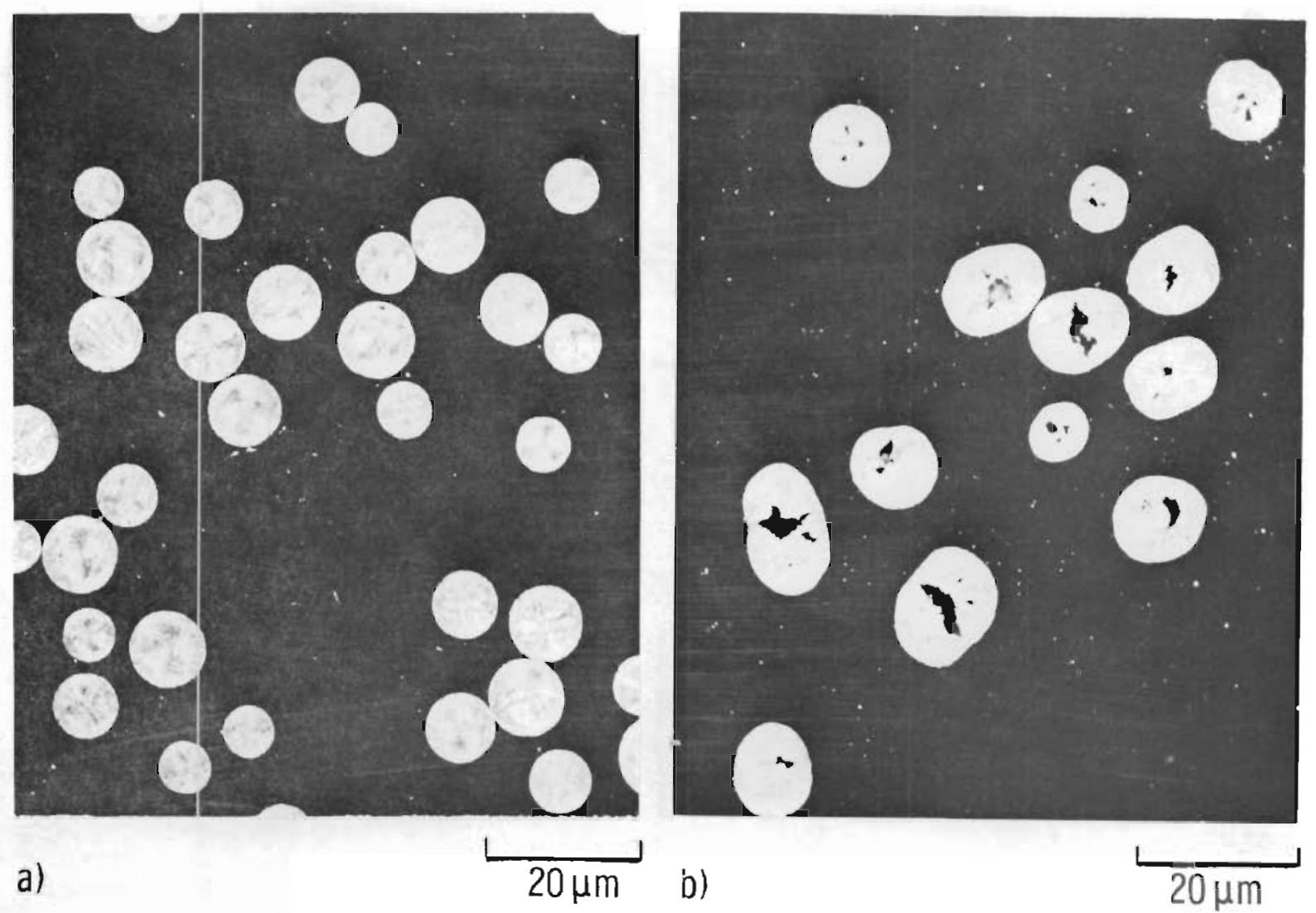
FIGURE 22. VSA-11 Graphite Fibers; a) Unirradiated,
b) $10 \times 10^{21} \mathrm{Cm}^{-2}$ 


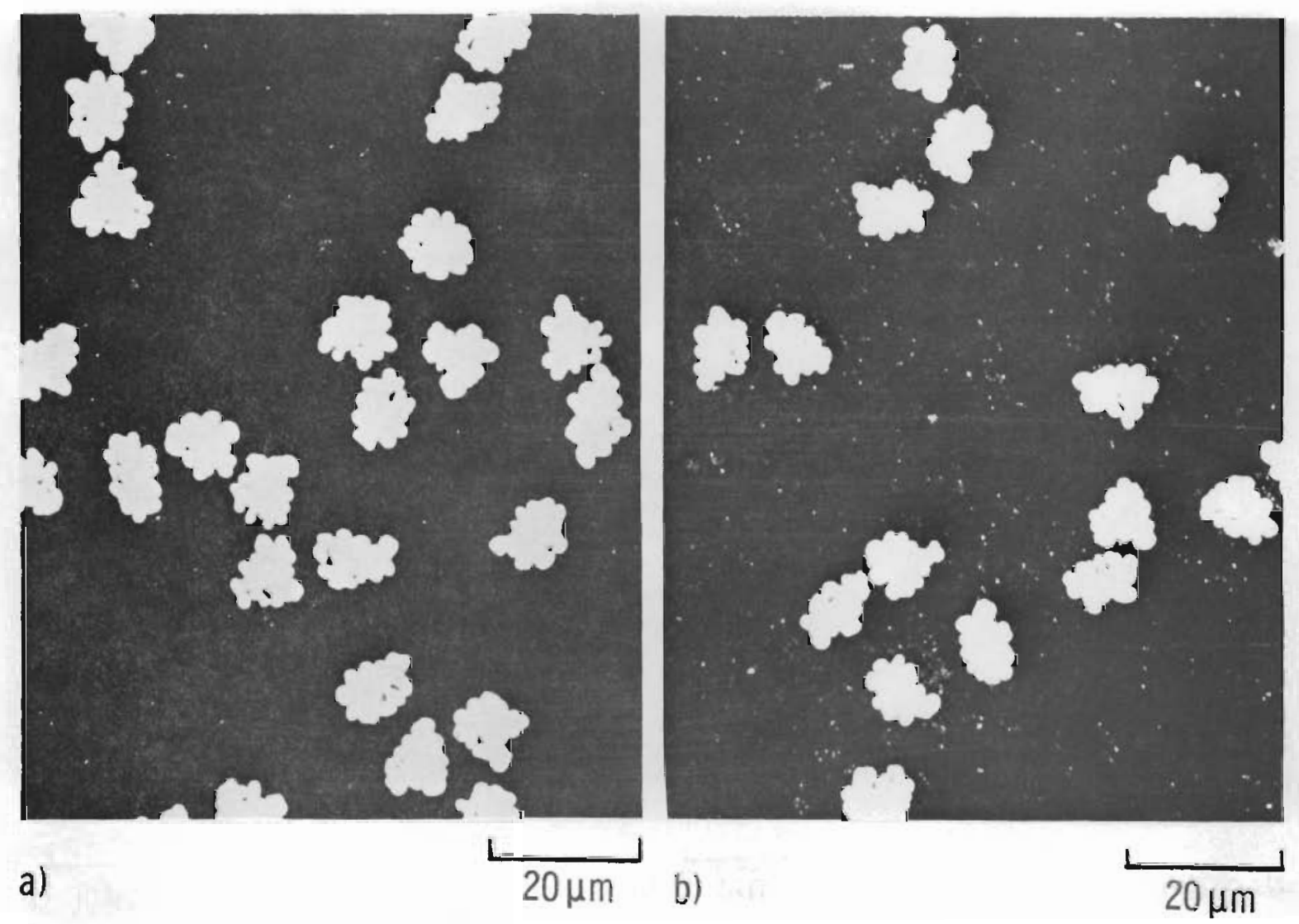

FIGURE 23. C-20 Carbon Fibers; a) Unirradiated, b) $10 \times 10^{21} \mathrm{~cm}^{-2}$ 


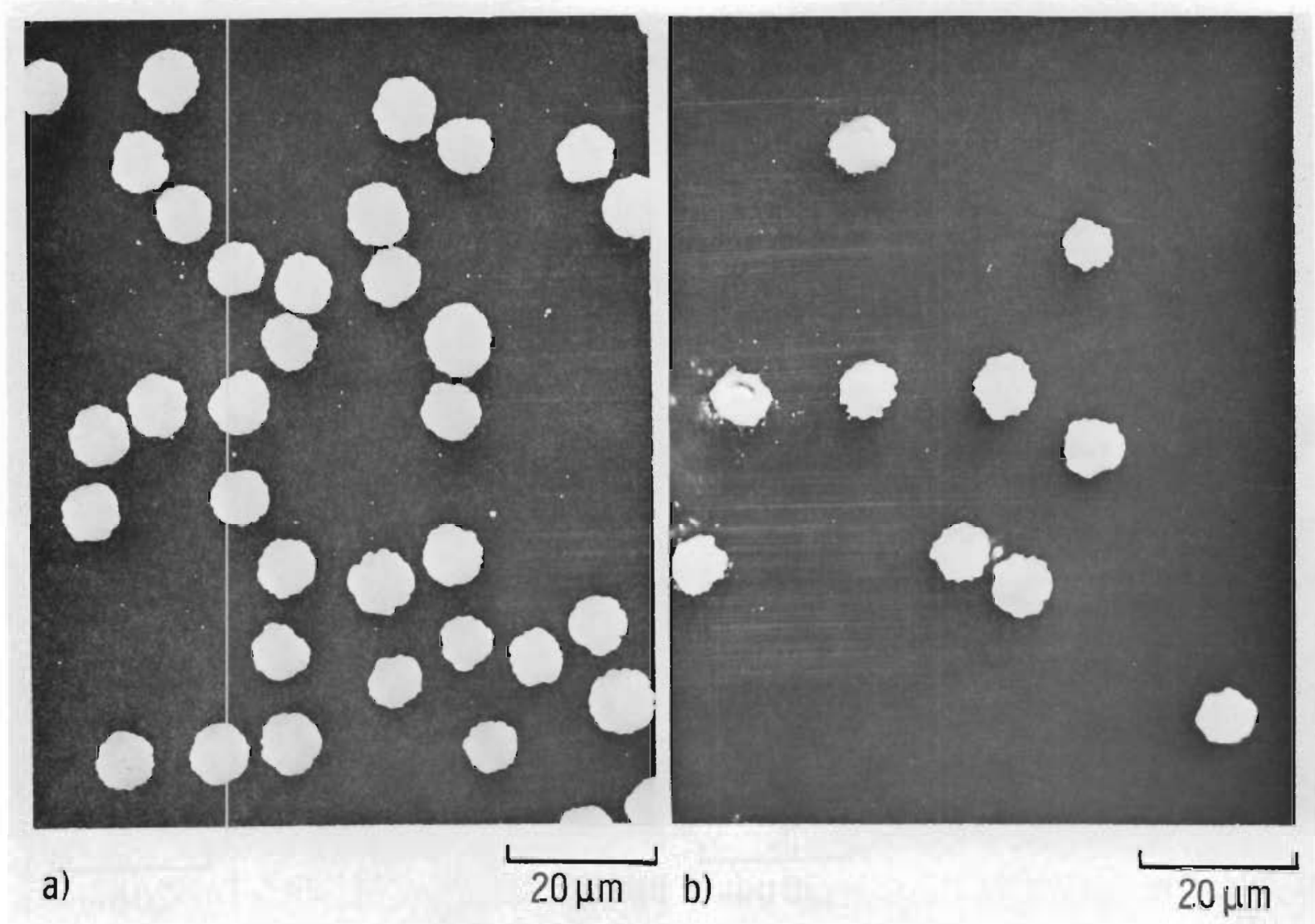

FIGURE 24. Type A Carbon Fibers; a) Unirradiated, b) $10 \times 10^{21} \mathrm{~cm}^{-2}$ 


\section{REFERENCES}

1. G. L. Kulcinski, et al., Nucl. Fusion, 15, 327 (1975); more details are in UWFDM-108 (1974).

2. R. W. Conn, et a1., Nuc7. Tech., 26, 125 (1975).

3. R. E. Nightingale, Nucl. Graphite, Academic Press, N.Y. (1962).

4. J. H. W. Simmons, Radiation Damage in Graphite, Pergamon Press, N.Y. (1965).

5. W. N. Reynolds, Chemistry and Physics of Carbon, P. L. Walker (ed.), Marce1 Dekkar, N.Y. (1966).

6. G. B. Engle and W. P. Eatherly, High Temp.-High Press, 4, 119 (1972).

7. W. C. Morgan and W. J. Gray, BNWL-1972 (1972).

8. W. J. Gray, W. C. Morgan, and G. L. Tingey, BNWL-2078 (1976).

9. I. D. Peggs and R. W. Mills, Tenth Biennial Conference on Carbon, Summary of Papers, pp. 188-189 (1971).

10. B. F. Jones, Ibid., pp. 190-191.

11. B. F. Jones and I. D. Peggs, J. Nucl. Mater., 40, 141 (1971).

12. R. E. Bullock, Rad. Effects, 11, 107 (1971).

13. B. J. Wicks, ARL/Met. -93 (1974).

14. ASTM Reconmended Practice E-525, Annual Book of ASTM Standards, Part 45.

15. W. C. Morgan, J. Nucl. Matl., 51, 209 (1974).

16. I. D. Peggs, Nature Phys. Sci., 235, 112 (1972).

17. W. J. Gray, Proceedings of the Second Topical Meeting on the Technology of Controlled Nuclear Fusion, Volume III, CONF-760935-P3, pp. 10491059 (Sept. 21-23, 1976).

18. J. B. Barr et a1., Applied Polymer Symposium No. 29, p. 161 (1976).

19. L. R. Bunne11, Rev. Sci. Instrum., 46, 1286 (1975).

20. J. A. Ulseth, Hanford Engineering Development Laboratory, Richland, Washington, personal communication.

21. W. C. Morgan, 11th Biennial Conference on Carbon, Extended Abstracts and Program, p. 296-297 (1973). 
22. W. C. Morgan and W. J. Gray, to be published in J. Nucl. Materials ca. January (1978).

23. J. W. He $1 \mathrm{~m}, \mathrm{BNWL}-1056 \mathrm{~A}$ and $B$ (1969).

24. A. L. Pitner, BNWL-1540 (1971).

25. A. L. Pitner, Carbon, 9, 637 (1971).

26. H. J. Fivel, G. P. Lang, and H. W. Kipp, C00-2802-4 (1976).

27. G. A. Beite1, J. Vac. Sci. and Tech. 6, 224 (1969). 
A. A. Churm

ERDA Chicago Patent Group

9800 5. Cass Ave.

Argonne, IL 60439

Assistant Director for Confinement Systems

ERDA Div. of Magnetic Fusion Energy

Washington, DC 20545

Assistant Director for Development and Technology

ERDA Div. of Magnetic Fusion Energy Washington, DC 20545

Chief, Materials and Radiation Effects Branch, D+T

ERDA Div. of Magnetic Fusion Energy

Washington, DC 20545

2 Chief, System Studies and Applications Branch, $D+T$

ERDA Div. of Magnetic Fusion Energy

Washington, DC 20545

Assistant Director for Plasma Physics

ERDA Div. of Magnetic Fusion Energy

Washington, DC 20545

Assistant Director for Technical Projects

ERDA Div. of Magnetic Fusion Energy

Washington, DC 20545

J. Baublitz

ERDA Div. of Hagnetic

Fusion Energy

Washington, DC 20545

J. W. Beal

ERDA Div. of Magnetic

Fusion Energy

Washington, DC 20545

L. Bogart

ERDA Div. of Magnetic Fusion Energy

Washington, DC 20545
M. M. Cohen

ERDA Div. of Magnetic

Fusion Energy

Washington, DC 20545

E.N.C. Dalder

ERDA Div, of Magnetics

Fusion Energy

Washington, DC 20545

J. F. Decker

ERDA Div. of Magnetic

Fusion Energy

Washington, DC 20545

C. R. Finfgeld

ERDA Div. of Magnetic

Fusion Energy

Washington, DC 20545

J. N. Grace

ERDA Div. of Magnetic

Fusion Energy

Washington, DC 20545

E. E. Kintner

ERDA Div. of Magnetic

Fusion Energy

Washington, DC 20545

R. N. Kostoff

ERDA Div. of Magnetic Fusion Energy

Washington DC 20545

J. V. Martinez

ERDA Div. of Magnetic

Fusion Energy

Washington, DC 20545

T. C. Reuther

ERDA Div. of ilagnetic

Fusion Energy

Washington, DC 20545

B. G. Twining

ERDA Div. of Magnetic

Fusion Energy

Washington, DC 20545

Dr. P. M. Stone

ERDA Applied Plasma

Physics Program

Washington, DC 20545

D. D. Mahlum

ERDA Div. of Biomedical and Environmental

Research

Washington, DC 20545
Assistant Director for Materials Sciences Program

ERDA Div. of Physical Research

Washington, DC 20545

Assistant Director for Technology

ERDA Div. of Reactor Research and Development

Washington, DC 20545

Chief, Fuel Systems Branch

ERDA Div. of Reactor Research and Development

Washington, DC 20545

Chief, ilaterials and Chemistry Branch,

Office of Technology,

ERDA Div. of Reactor

Development and Demonstration

Washington, DC 20545

ERDA Technical Information Center

Joseph B. Darby, Jr.

Building 208

Argonne National Laboratory

4700 S. Cass Avenue

Argonne, IL 60439

Samuel D. Harkness

Building 208

Argonne National

Laboratory

4700 S. Cass Avenue

Argonne, IL 60439

2

W. M. Stacey, Director, ANL Fusion Power Program,

Building 208

Argonne National

Laboratory

9700 S. Cass Ave.

Argonne, IL 60439

Director, Materials

Science Division

Argonne National

Laboratory

9700 S. Cass Âve.

Argonne, IL 60439 
D. M. Gruen

Argonne National

Laboratory

9700 S. Cass Avenue

Argonne, IL 60439

R. Heinrich

Argonne National

Laboratory

9700 5. Cass Ave.

Argonne, IL 60439

M. S. Kaminsky

Argonne National Laboratory

9700 5. Cass Ave.

Argonne, IL 60432

V. H. Maroni

Argonne ilationa 1

Laboratory

9700 S. Cass Ave.

Argonne, IL 60439

F. V. Nolfi

Argonne ivational

Laboratory

9700 S. Cass Ave.

Argonne, IL 60439

P. M. Persiani

Argonne National Laboratory

9700 S. Cass Ave.

Argonne, IL 60439

M. Petrick

Engineering and Technology Division

Argonne National

aboratory

9700 S. Cass Ave.

Argonne, IL 60439

Manager, Materials and Physics Technology

Atomics International

Component Engineering and Technology Division

North American Rockwell

8900 DeSoto Ave.

Canoga Park, CA 91304

D. Kramer

Atomics International

Component Engineering and

Technology Division

North American Rockwell

8900 Desoto Ave.

Canoga Park, CA 91304

H. Farrar

Atomics International

Component Engineering and

Technology Division

North American Rockwell

8900 Desoto Ave.

Canoga Park, CA 91304
W. E. Parkins, Manager

Atomics International

Component Engineering and

Technology Division

North American Rockwell

P.0. Box 309

Canoga Park, CA 91304

Chairman, Department of Applied Sciences

Brookhaven National Laboratory

Associated Universities

Upton, NY 11973

Associate Chairman for Chemistry and Materials Programs, Department of Applied Sciences

Brookhaven Ilational Laboratory

Associated Universities

Upton, NY 11973

A. N. Goland

Brookhaven National

Laboratory

Associated Universities

Upton, NY 11973

D. Gurinsky

Brookhaven Nationa 1 Laboratory

ERDA Brookhaven Area Office

Upton, NY 11973

S. Pearlstein

Brookhaven National Laboratory

ERDA Brookhaven Area Office

Upton, NY 11973

J. R. Powe 11

Brookhaven Vational Laboratory

ERDA Brookhaven Area Office

Upton, NY 11973

A. J. Impink: Ir Carnegie Melion University Pittsburgh, PA 15213

R. A. Gross

Plasma Physics Laboratory

236 SW Mudd Bldg.

Columbia University

liew York, NY 10027

R. J. Tien

Plasma Physics Laboratory

Columbia University

New York, NY 10027
C. Y. Li

Cornel1 University

Ithaca, NY 14850

Program Manager for Fusion Power

Electric Power Research Institute

3412 Hillview Ave.

Palo Alto, CA 94304

H. C. Gough

Electric Power Research Institute

3412 Hillview Ave.

Palo Alto: CA 94304

Manager, Fusion

Engineering Department

Gulf General Atomic Co.

P.O. Box 81608

San Diego, CA 92138

G. B. Engle

Gulf General Atomic Co. P.0. Box 81608

San Diego, CA 92138

G. R. Hopkins

Gulf General Atomic Co.

P.0. Box 81608

San Diego, CA 92138

L. Rovner

Gulf General Atomic Co.

P.0. Box 81608

San Diego, CA 92138

Zeinab Sabri

Nuclear Engineering Department

261 Sweeney Hal1

Iowa State University

Ames, IA 50010

Chief, Materials and Process Department Grumman Aerospace Corp. Bethpage, NY 11714

M. D. D'Agostino Director, ivuclear and Astrophysics Research Grumman Aerospace Corp. Research Dept. Bethpage, iN 11714

H. K. Forsen

Jersey Nuclear Company

777 106th Ave, NE

Bellevue, WA 98004

Director, CTR Division

Lawrence Livermore Laboratory

P. 0. Box 808

Livermore, CA 94550 
Director, E Division

Lawrence Livermore

Laboratory

P.0. Box 808

Livermore, CA 94550

Program Manager for CTR, Chemistry and Materials

Sciences Department

Lawrence Livermore

Laboratory

P.0. Box 808

Livermore, CA 94550

R. Borg

Lawrence Livermore Laboratory

P.0. Box 808

Livermore, CA 94550

T. K. Fowler

Lawrence Livermore Laboratory

P.0. Box 808

Livermore, CA 94550

A. C. Haussmann

Lawrence Livermore Laboratory

P.0. Box 808

Livermore, CA 94550

A. L. Hunt

Lawrence Livermore Laboratory

P.0. Box 808

Livermore, CA 94550

C. J. Taylor

Lawrence Livermore Laboratory

P.0. Box 308

Livermore, CA 94550

R. VanKonynenburg Lawrence Livermore Laboratory

P.0. Box 808

Livermore, CA 94550

L. L. Wood

Lawrence Livermore Laboratory

P.0. Box 808

Livermore, CA 94550

Division Leader,

CTR Division

Los Alamos Scientific Laboratory

P.0. Box 1663

Los Alamos, NM 87544
Division Leader,

CMB Division

Los Alamos Scientific Laboratory

P.0. Box 1663

Los Alamos, NM 87544

Division Leader,

$P$ Division

Los Alamos Scientific

Laboratory

P.0. Box 1663

Los Alamos, NM 87544

F. W. Clinard

Los Alamos Scientific Laboratory

P.0. Box 1663

Los Alamos, NM 37544

D. J. Dudziak

Los Alamos Scientific Laboratory

P.0. Box 1663

Los Alamos, NM 87544

C. R. Emigh

Los Alamos Scientific Laboratory

P.0. Box 1663

Los Alamos, NM 87544

W. Green

Los Alamos Scientific Laboratory

P.0. Box 1663

Los Alamos, NM 87544

D. B. Henderson

Los Alamos Scientific Laboratory

CTR Division

P.0. Box 1663

Los Alamos, NM 87544

L. Stewart

Los Alamos Scientific Laboratory

CTR Division

P.0. Box 1663

Los Alamos, NM 87544

Bruno Coppi

Department of Physics

Massachusetts Institute of Technology

Cambridge, MA 02139

0. K. Harling

Massachusetts Institute of Technology

Cambridge, MA 02139
L. Lidsky, Department of Nuclear Engineering

Massachusetts Institute of Technology

Cambridge, MA 02139

David Rose

Massachusetts Institute of Technology

Cambridge, MA 02139

K. Russe11, Department of Materials Science

Massachusetts Institute of Technology

Cambridge, IA 02139

D. Krummer

icDonnel1-Douglas Astronautics

P. 0 . Box 516

St. Louis, MO 63166

G. P. Lang

MCDonnell-Douglas Astronautics

P.0. Box 516

St. Louis, ino 63166

Manager, Technology Applications and Development

Mound Laboratory

P.0. Box 32

iliamisburg, $\mathrm{OH} 45342$

J. J. Reinmann

NASA - Lewis Research Center

2100 Bookpark Rd.

Cleveland, $\mathrm{OH} 44135$

Director, Center for Radiation Research ilational Bureau of Standards

Room C-225

Washington, DC 20234

Vincent Arp

National Bureau of Standards

Cryogenics Division

Boulder, CO 80302

T. S. Elleman

North Carolina State University

Department of Nuclear Engineering

Raleigh, NC 26707 
Director, Thermonuclear Division, Bldg. 9201-2

Oak Ridge liational Laboratory

P.0. Box $Y$

Oak Ridge, TN 37830

Director, Metals and Ceramics Division

Oak Ridge National Laboratory

P.0. Box Y

Oak Ridge, TN 37830

Program Manager, Fusion Reactor Technology Program

Bldg. 9204-1

Oak Ridge National Laboratory

P.0. Box Y

Oak Ridge, TN 37830

J. L. Scott, Manager Magnetic Fusion Energy Materials

Metals and Ceramics Division

Bldg. 4500 SM, S-178

P.0. Box X

Oak Ridge, TN 37830

B. R. Appleton

Oak Ridge National Laboratory

P.0. Box Y

Oak Ridge, TN 37830

E. E. Bloom

Oak Ridge National

Laboratory

P.0. Box $Y$

Oak Ridge, TN 37830

C. R. Brinkman

Oak Ridge National Laboratory

P.0. Box Y

Oak Ridge, TN 37830

R. J. Colchin

B1dg. 9201-2

Oak Ridge National Laboratory

P.0. Box Y

Oak Ridge, TN 37830

J. H. Devan

Bldg. 4500S

Oak Ridge National Laboratory

Oak Ridge, TN 37830

W. P. Eatherly

Oak Ridge National Laboratory

P.0. Box X

Oak Ridge, TN 37830
A. P. Fraas

Oak Ridge National

Laboratory

P.0. Box Y

Oak Ridge, TN 37830

J. A. Horak

Bldg. 4500 S

Oak Ridge National Laboratory

Oak Ridge, TN 37830

W. R. Martin

Bldg. 4500s

Oak Ridge National Laboratory

P.0. Box $Y$

Oak Ridge, TN 37830

J. Rand McNally, Jr. Oak Ridge National Laboratory

P.0. Box Y

Oak Ridge, TN 37830

M. Roberts

B1dg. 9204-1

Oak Ridge Nationa 1

Laboratory

P.0. Box Y

Oak Ridge, TN 37830

R. Werner

Oak Ridge National

Laboratory

P.0. Box $X$

Oak Ridge, TN 37830

F. W. Wiffen

Bldg. 45005

Oak Ridge National

Laboratory

P.0. Box Y

Oak Ridge, TN 37830

R. Cooper

Physics International

2700 Merced St.

San Leandro, CA 94577

R. A. Huse

Public Service Electric and Gas Co.

80 Park Place

Newark, NJ 07101

H. Perkins

Department of Chemistry

Princeton University

Princeton, iN 06540

Director, Plasma Physics Laboratory

Princeton University

Princeton, NJ 06540
Project Manager, TFTR

Plasma Physics Laboratory

Princeton University

Box 451

Princeton, NJ 08540

S. Cohen

Plasma Physics Laboratory

Princeton University

Box 451

Princeton, NJ 08540

R. G. Mills

Plasma Physics Laboratory

Princeton University

Box 451

Princeton, NJ 08540

C. Osgood

Plasma Physics Laboratory Princeton University

Box 451

Princeton, NJ 08540

E. C. Tanner

Plasma Physics Laboratory

Princeton University

Box 451

Princeton, NJ 08540

K. Wakefield

Plasma Physics Laboratory

Princeton University

Box 451

Princeton, iN 08540

2 W. Bauer

Division Supervisor of

Physical Research

Sandia Laboratories

Livermore, CA 94550

2 S. L. Vook

Sandia Laboratories

A1buquerque, NM 37115

M. Kristiansen

Texas Tech. University

Lubbock, TX 79409

R. Bacon

Union Carbide Corp.

Parma Technical Center

Box 6116

Cleveland, $\mathrm{OH} 44101$

A. F. Haught

United Aircraft Research Laboratory

United Aircraft Corp.

East Hartford, CT 06108 
Head, Thermo Structural Materials Branch

U.S. Nava 1 Research Laboratory

Metallurgy Division Code 6390

Washington, DC 20390

F. Smidt

U.S. Naval Research Laboratory

Metallurgy Division

Code 6390

Washington, DC 20390

L. Levine

U.S. Naval Research

Laboratory

Washington, DC 20390

C. Z. Serpan, Jr.

U.S. Naval Research

Laboratory

Washington, DC 20390

Francis Chen

UCLA School of Engineering and Applied Science

Boelter 7731

Los Angeles, CA 90024

A. J. Lichtenberg University of California

Electronics Research

Laboratory

College of Engineering

Berkeley, CA 94720

\section{J. Moteff}

University of Cincinnati

Department of Materials

Science and Metullurgical

Engineering

Location 12

Cincinnati, $\mathrm{OH} \quad 45221$

C. D. Hendricks

University of Illinois

ivuclear Engineering

Laboratory

Urbana, IL 6180 ?

G. H. Milev

University of 111 inois

Nuclear Engineering

Department

Ann Arbor, MI 48105

Terry Kamash

University of Michigan

Nuclear Engineering Department

Ann Arbor, MI 48105

Dean Abrahamson

University of Minnesota

School of Public Affairs

Social Science Building/309

Minneapolis, 隹 55455
W. G. Davey

University of Texas

Department of Physics

Austin, TX 72712

E. Linn Draper, Jr.

University of Texas

Department of Physics

Austin, TX 78712

W. E. Drummond

University of Texas

Department of Physics

Austin, TX 78712

H. G. F. Wilsdorf

University of Virginia

Department of Materials Science

Research Labs for

Engineering Sciences

Charlottesville, VA 22901

Abraham Hertzberg

University of Washington

Aerospace Research Laboratory

316 Guggenheim

Seattle, WA 98105

A. L. Babb

University of Washington

Nuclear Engineering

Department

Seattle, WA 92105

R. Conn

University of Wisconsin

iVuclear Eng ineering

Department

iladison, WI 53706

G. L. Kulcinski

University of Wisconsin

Nuclear Engineering Department

Madison, WI 53706

C. W. Maynard

University of Wisconsin

Nuclear Engineering

Department

Madison, $\mathrm{Wi} 53706$

D. Lichtman

Department of Physics

University of Wisconsin

Milwaukee, WI 53201

E. E. Donaldson

Washington State

University

Department of Physics

Pullman, WA 99163

Manager, Fusion Power

Systems Department

Westinghouse Electric Corp.

P.0. Box 355

Pittsburgh, PA 15230
R. Gold

Westinghouse Electric

Corp.

Research and Development

Center

Beulah Road

Pittsburgh, PA 15234

J. R. Holland

Westinghouse Electric

corp.

Beulah Road

Pittsburgh, PA 15234

ONSITE

ERDA Richland Operations Office

W. A. Burns

Rockwell Hanford Operations

J. D. Kaser

Hanford Engineering

Devlopment Labs

Manger, Materials

Engineering

H. H. Yoshikawa

Battelle-Northwest

L. R. Bunnel1

T. D. Chikalla

R. L. Dillon

5 D. A. Dingee

15 W. J. Gray

A. B. Johnson, Jr.

W. C. Morgan

R. D. Nelson

R. E. Nightingale

L. C. Schmid

A. M. Sutey

G. L. Tingey

M. T. Thomas

E. M. Woodruff

Techical Pulications (BH)

Technical Information (5) 
. 